ISSN: 0514-7336

DOI: http://dx.doi.org/10.14201/zephyrus201474157179

\title{
PRÁCTICAS RITUALES IBÉRICAS EN LA CUEVA DEL SAPO (CHIVA, VALENCIA): MÁS ALLÁ DEL CALICIFORME
}

\section{Iberian Ritual Practices in Cueva del Sapo (Chiva, Valencia): Beyond the Calyx-cup}

\author{
Sonia Machause López*, Ángela Pérez Fernández**, Paloma Vidal Matutano* y Alfred Sanchis Serra*** \\ * Dpto. de Prehistoria y Arqueología. Facultad de Geografía e Historia. Avda. Blasco Ibáñez, 28. 46010 Valencia. \\ Correo-e: sonia.machause@uv.es; paloma.vidal@uv.es \\ ** Dpto. de Medicina Legal, Toxicología y Antropología Física. Facultad de Medicina. Avenida de Madrid, 11. \\ 18012 Granada. Correo-e: angelaperez@ugr.es \\ *** Museo de Prehistoria de Valencia. SIP. Cl Corona, 36. \\ 46003 Valencia.Correo-e: alfred.sanchis@dival.es
}

Recepción: 4/3/2014; Revisión: 26/07/2014; Aceptación: 14/09/2014

BIBLID [0514-7336 (2014) LXXIV, julio-diciembre; 157-179]

Resumen: Se presentan los resultados del estudio interdisciplinar del yacimiento ibérico de la Cueva del Sapo (Chiva, Valencia). Las características del conjunto estudiado muestran un contexto ritual que sería frecuentado entre los ss. V-II a. C. La diversidad cronológica y material así como el volumen de restos indican la existencia de varias actividades rituales intermitentes, no generalizadas y que se suceden en el tiempo. Nos acercamos a ellas a través de la presencia de restos de fauna, con escasas evidencias de consumo que reflejan un ritual principal en torno a la figura del ciervo, huesos humanos sin incinerar con marcas que demuestran un tratamiento concreto del cadáver ligado a un complejo ritual funerario en época ibérica y otros materiales -cerámicas, metales y carbones- que también son pruebas de una actividad ritual en la cueva, cuyas características difieren de los criterios tradicionales establecidos para las cuevas con materiales ibéricos. Todos estos factores nos hacen replantearnos la definición tradicional, todavía vigente, para este tipo de contextos rituales, cargada en algunas ocasiones de excesivas generalizaciones.

Palabras clave: Época ibérica; Ritualidad; Cuevas-santuario; Arqueozoología; Antropología; Antracología.

AвSTRACT: In this paper we present the results of a interdisciplinary study in the Iberian site of Cueva del Sapo (Chiva, Valencia). The features of the assemblage have brought to light a very complex ritual context which would be frequented among the vth and Innd centuries вс. The chronological and material diversity, as well as the volume of remains, indicate the existence of several intermittent ritual activities, not generalized and successive over time. We approach them through the presence of faunal remains with limited evidence of consumption which reflect a ritual about red deer, not incinerated human bones which show a particular process of the corpse related to a complex funerary ritual in the Iberian Iron Age and other materials such as pottery, metal and charcoal, which show a ritual activity in the cave. Whose characteristics differ from the traditional criteria established for the caves with Iberan materials. All these factors make us reconsider the traditional definition, still in force, for this kind of ritual contexts, sometimes full of excessive generalization.

Key words: Iberian Iron Age; Rituality; Cave-shrines; Archaeozoology; Anthropology; Charcoal analysis. 


\section{Introducción ${ }^{1}$}

El interés sobre el estudio de cuevas con materiales ibéricos situadas en los actuales territorios de Cataluña, Murcia y, sobre todo, País Valenciano, surgió a finales del s. XIX, pero no fue hasta los años 70 del s. xx cuando, gracias a los trabajos de M. Tarradell (1973) y de M. Gil-Mascarell $(1975)^{2}$, se establecieron unos rasgos comunes que las definían como lugares de culto. A partir de este momento, los estudios comenzaron a multiplicarse. Se realizaron investigaciones muy completas sobre cuevas como las del Puntal del Horno Ciego (Gil-Mascarell, 1977; Martí Bonafé, 1990) y sobre algunos de sus materiales como los vasos caliciformes o los restos de fauna de la Cueva Merinel (Martínez Perona, 1992; Blay, 1992), entre otros. Se ampliaron las investigaciones a nivel regional, centrándose en determinados ámbitos geográficos (Aparicio, 1976; Vega, 1981; Serrano y Fernández, 1992). Y a nivel global, a través de las sistematizaciones generales de T. Moneo (2003) y J. Aparicio (1997), así como los diversos estudios de J. González-Alcalde, quien además comenzó a relacionarlas, basándose en su

${ }^{1}$ Este estudio estuvo motivado en origen por el trabajo final del Máster de Arqueología de la Univ. de Valencia de la primera firmante, dirigido por C. Mata y presentado en julio de 2012. S. Machause disfruta de una Beca 'Atracció de Talent' de la Univ. de Valencia (vLC-CAmpus) y P. Vidal de Beca 'vali+d' de la Generalitat Valenciana. Queremos agradecer al Museo de Prehistoria de Valencia las facilidades prestadas a la hora de revisar el conjunto de materiales presentados. Asimismo damos las gracias a todas aquellas personas que han participado en el desarrollo de esta investigación. En especial a J. Vives-Ferrándiz por su disponibilidad diaria y consejo en el estudio cerámico; a G. Tortajada por sus orientaciones sobre los materiales metálicos; a J. Bernabeu por hacer posibles los análisis de $\mathrm{C}^{\mathrm{I} 4}$ de los restos humanos, y a Y. Carrión por el estudio de parte de la muestra antracológica. Damos las gracias también a F. Blay por la localización de la cueva y su apoyo durante la visita a la misma; a D. Quixal por la documentación fotográfica y georreferencial de la cueva; a A. Díez por su ayuda con la parte cartográfica del trabajo. Muy especialmente agradecemos a C. Mata la coordinación en todo momento de esta investigación y que nos haya abierto los ojos hacia un yacimiento que no ha dejado de sorprendernos en ningún momento.

${ }^{2}$ Cf. también Gil-Mascarell, M. (1971): Yacimientos ibéricos en la Región Valenciana. Estudio del poblamiento. Tesis doctoral inédita, presentada en 1971 en la Univ. de Valencia. situación, su morfología y los materiales documentados en ellas, con ritos de paso similares a los que se conocen en otras culturas del Mediterráneo (1993, 2002-2003, 2005, 2006, 2009, 2013).

Aun así, la mayoría de estos trabajos siempre se han realizado bajo un enfoque de compendio. En general, no presentan las características específicas de cada cueva, ni su relación con otros lugares de culto en un mismo territorio, a excepción de estudios como el de las Cuevas del Puntal del Horno Ciego (Martí Bonafé, 1990), el de la Cova dels Pilars (Grau, 1996; Grau y Olmos, 2005), la Cueva Santa del Cabriel (Lorrio et al., 2006), la Cova de l'Agüela (Amorós, 2012), el santuario rupestre de La Nariz (Ocharán, 2013; González Reyero et al., 2014) o la investigación sobre los lugares de culto en el área central de la Contestania (Grau, 2000; Grau y Amorós, 2013). Otra de las carencias que presentan generalmente este tipo de estudios es la ausencia de un análisis del conjunto de sus materiales, más allá del mero inventario de los vestigios cerámicos y/o metálicos.

Además, en el análisis de este tipo de cuevas, nos enfrentamos a otras limitaciones como, por ejemplo, la existencia de una ocupación continuada, generalmente carente de estratigrafía y afectada por una gran diversidad de eventos postdeposicionales. Este hecho hace que su interpretación sea bastante problemática, y en muy pocas ocasiones se cuestione la posible adscripción de restos humanos que aparecen en algunas de las cuevas con momentos de frecuentación en época ibérica -ss. VI-I a. C.-.

\section{El yacimiento}

La Cueva del Sapo se localiza en el término municipal de Chiva (Valencia), concretamente en la ladera NE del cerro de la Atalaya, también conocido como Montico Redondo, aproximadamente a una altitud de 500 m.s.n.m. En la actualidad, esta zona se enmarca dentro del Paraje Natural de la Sierra de Chiva, perteneciente al dominio estructural del Sistema Ibérico, entre la Sierra de las Cabrillas y la Sierra de los Bosques (Fig. 1). La cueva está formada a partir de una diaclasa principal (SO-NE) y otra de nivel secundario, más pequeña ( $\mathrm{E}$ ) (Pla Ballester, 1985: 57). El acceso actual a la cavidad se realiza descendiendo unos $3 \mathrm{~m}$ por una abertura de $2 \mathrm{~m}$ de 

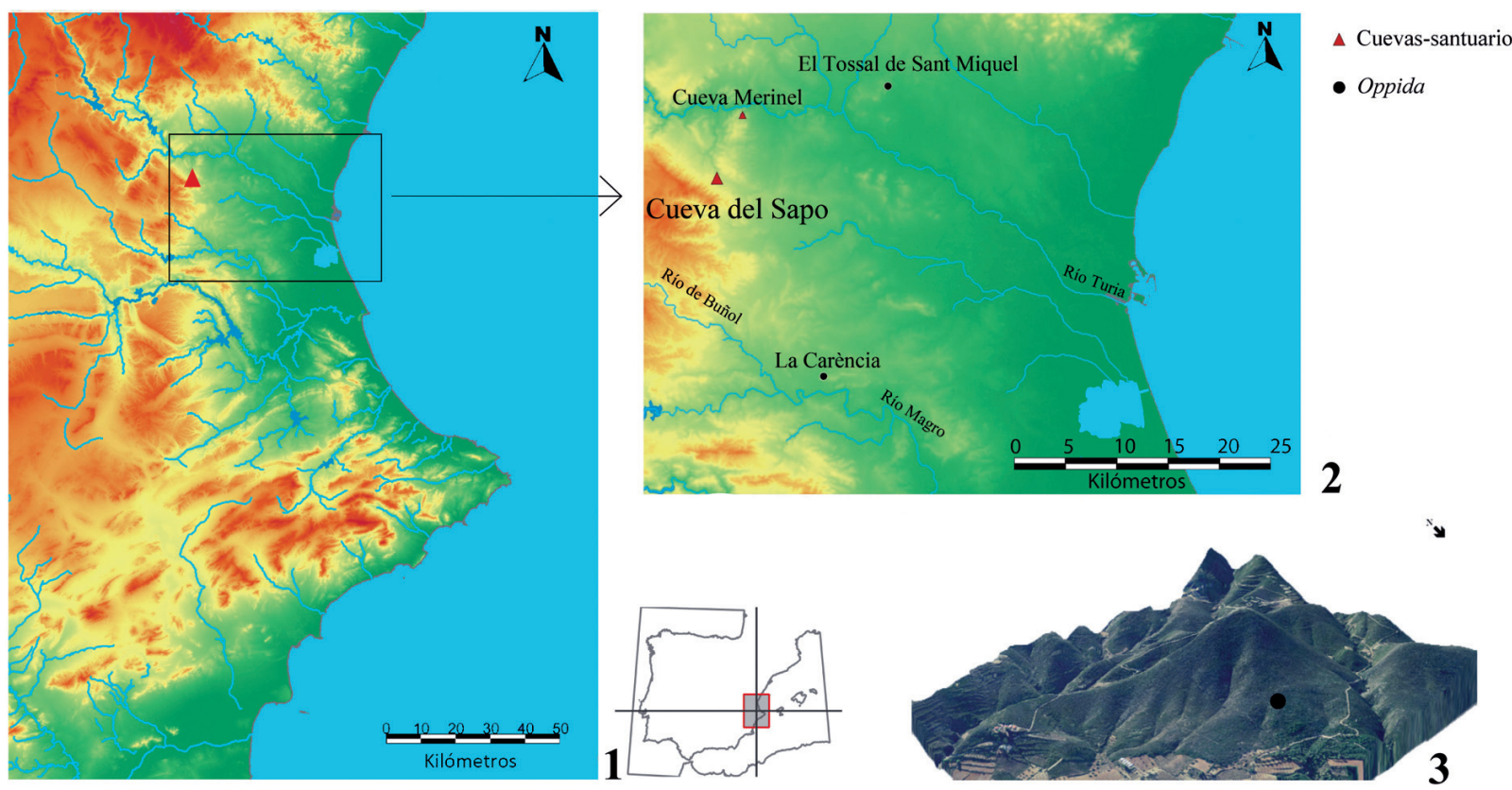

Fig. 1. Localización de la Cueva del Sapo: 1. Situación del yacimiento; 2. Localización de la cueva en relación a los grandes oppida ibéricos y otras cuevas con evidencias rituales; 3. Vista en $3 D$ del entorno del yacimiento.

diámetro aproximadamente. La cueva está formada por una estrecha galería que recorre a ambos lados de la entrada actual, con una longitud de unos 20 $\mathrm{m}$ y una anchura de 1-1,5 $\mathrm{m}$. La parte que se dirige hacia el NE mide unos $12 \mathrm{~m}$ de largo, presenta un elevado desnivel y está repleta de estalactitas; mientras que hacia el so existe una galería secundaria de unos $8 \mathrm{~m}$ de largo, algo más estrecha y de menor pendiente, donde pensamos que se localizaría la entrada original, actualmente bloqueada por un desprendimiento (Fig. 2).

El descubrimiento del yacimiento se produjo por parte de un grupo de aficionados, quienes en 1983 depositaron los materiales hallados en el Dpto. de Prehistoria y Arqueología de la Univ. de Valencia. Estos restos fueron los que abrieron la problemática principal del yacimiento, ya que eran materiales típicamente ibéricos, entre los que se encontraban también restos humanos sin señales de incineración. Temiendo que se realizaran nuevas actuaciones clandestinas que afectaran al sedimento y a los materiales de la cueva, C. Aranegui y E. Portell realizaron un sondeo de urgencia ese mismo año (Pla Ballester, 1985). La intervención se centró en dos lugares que no se habían visto afectados por las remociones mencionadas. Por una parte, se realizó el sondeo I -catas A y B- al lado de la zona removida, al final de la pendiente de acceso, donde se había acumulado la mayoría de materiales, mientras que el sondeo II -catas C y D- se efectuó en la galería secundaria de la parte alta, a la izquierda de la entrada actual (Pla Ballester, 1985) (Fig. 2).

Las características uniformes del sedimento y la existencia de varios fragmentos cerámicos de un mismo vaso en capas muy alejadas confirmaron la presencia de un solo nivel estratigráfico, debido tanto a la remoción natural vinculada a la topografía de la cueva, como a las alteraciones producidas por los clandestinos (Portell, 1983) ${ }^{3}$.

\section{Metodología aplicada}

La existencia de un único nivel estratigráfico en la cueva justifica el estudio de los materiales desde un enfoque global, sin tener en cuenta las capas artificiales excavadas durante la intervención de urgencia. Los resultados del estudio multidisciplinar

3 Portell, E. (1983): Informe preliminar sobre el sondeo de urgencia realizado en la "Cova del Sapo", Chiva (Valencia). Informe inédito depositado en 1983 en el sip de Valencia. 

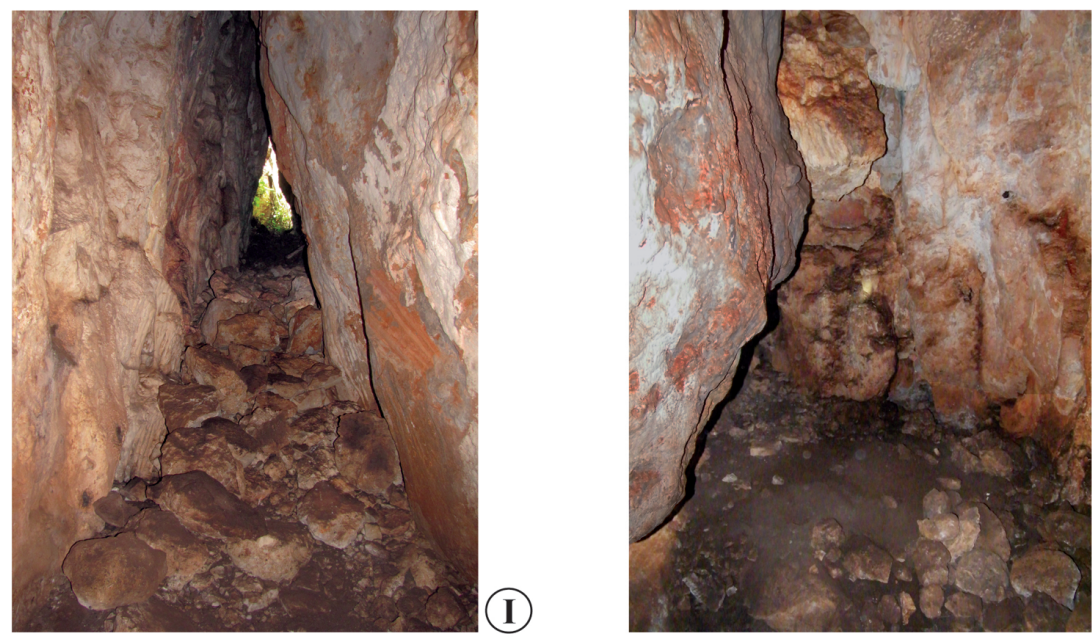

(II)
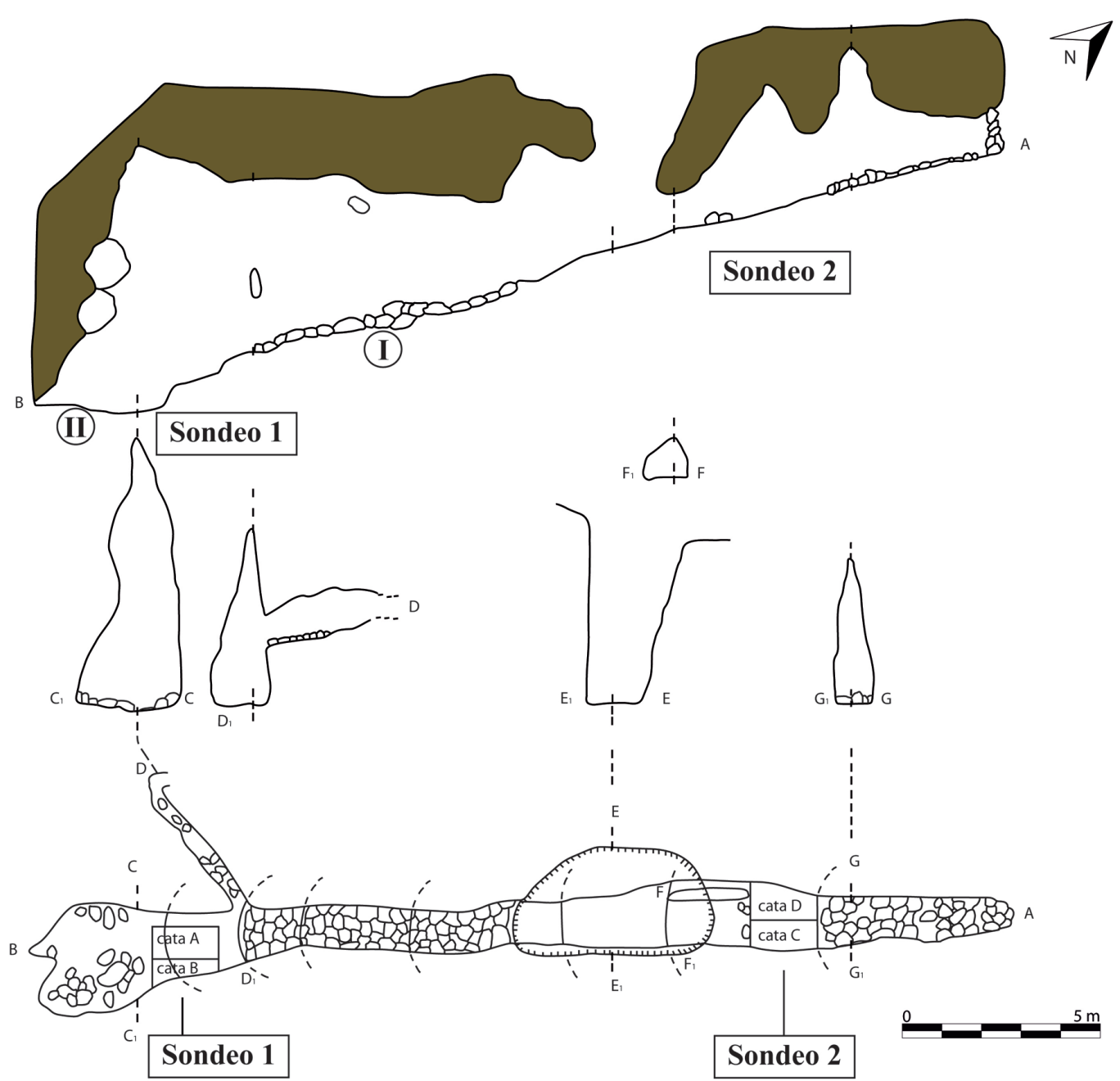

FIG. 2. Fotografias del interior de la cueva (fotos D. Quixaly S. Machause) y planimetría del yacimiento (a partir de Portell, 1983). 
que presentaremos a continuación hacen referencia al conjunto de los materiales hallados en superficie por los aficionados y aquellos recuperados durante la excavación, actualmente depositados en el Museo de Prehistoria de Valencia.

En el estudio cerámico se ha seguido el ensayo tipológico sobre la cerámica ibérica de Mata y Bonet (1982), estableciendo el número mínimo de individuos-NMI-, en relación al recuento total de formas, basándose en los bordes en primer lugar, seguidos de las bases y las asas. Para las apreciaciones cronológicas se han tenido en cuenta los poblados con niveles bien datados o con un solo momento de ocupación, como, por ejemplo: Kelin/Los Villares (Caudete de las Fuentes, Valencia) (Mata, 1991; Vidal Ferrús et al., 1997); El Oral (San Fulgencio, Alicante) para finales del s. vi-v a. C. (Abad y Sala, 1993); la fase de finales del s. v- 1.a mitad de s. IV a. C. del Castellet de Bernabé (Llíria, Valencia) (Guérin, 2003) y de la Lloma del Manoll (Llíria, Valencia) (Bonet y Mata, 1997a); el Pla de Piquer (Alfara d'Algímia, Valencia) (Aranegui y Martí Bonafé, 1995) y la Bastida de les Alcusses (Moixent, Valencia) (Fletcher, 1965, 1969; Díes et al., 1997) para el s. IV a. C.; y los niveles del s. III a. C. del Tossal de Sant Miquel (Llíria, Valencia) (Bonet, 1995) y de Covalta (Albaida, Valencia) (Raga, 1995), entre otros.

La clasificación de los objetos metálicos se ha realizado basándose, entre otros, en los trabajos sobre armamento de Quesada (1997) y los estudios sobre fíbulas de Cuadrado (1978), Cabré y Morán (1979, 1982) e Iniesta (1983). Para la identificación de las herramientas en hierro, se han utilizado principalmente las publicaciones de $\mathrm{Pla}(1968)$ y Tortajada (2012).

El material antracológico ha sido analizado siguiendo la metodología propia de la disciplina (Badal y Heinz, 1991; Chabal, 1997). Con el fin de identificar la anatomía vegetal, cada fragmento ha sido observado utilizando un microscopio óptico de luz reflejada de campo claro-oscuro, con objetivos de 100 a 500 aumentos, para posteriormente ser comparado con la bibliografía especializada (Jacquiot et al., 1973; Schweingruber, 1990) y con una colección de referencia de maderas quemadas. Finalmente, la toma de fotografías de detalles anatómicos se ha realizado en el Microscopio Electrónico de Barrido (Hitachi s-4100), situado en el Servicio Central de Soporte a la Investigación Experimental
(sCSIE), laboratorio de microscopía electrónica de la Univ. de Valencia.

En el análisis de los restos humanos se han clasificado cada uno de los elementos óseos teniendo en cuenta: taxón, lado, número de fragmentos observados, sexo, edad y observaciones, entre otros. Los huesos se han analizado macroscópicamente. La estimación del número mínimo de individuos -NMI- se ha realizado a partir de la frecuencia de cada hueso y su lateralidad, teniendo en cuenta la madurez o inmadurez esquelética. La identificación del sexo en individuos adultos se ha establecido a través de los caracteres cualitativos, fundamentalmente a partir de las características morfológicas del cráneo y la mandíbula (Ferembach et al., 1980). También se han aplicado parámetros cuantitativos, basados en las dimensiones de los huesos largos (Alemán et al., 1997) y de los dientes ${ }^{4}$. Los criterios empleados para la estimación de la edad se han ajustado a las características de la muestra (Cunha et al., 2009). Se ha empleado el grado de sinóstosis o fusión de las epífisis de los huesos largos (Brothwell, 1987) y el grado de obliteración de las suturas craneales (Olivier, 1960; Meindl y Lovejoy, 1985). Las alteraciones tafonómicas observadas incluyen fracturas post mortem, roeduras de animales y marcas de corte sobre el hueso. La identificación de los indicadores tafonómicos se hizo a partir de los criterios establecidos por Binford (1981), Pérez Ripoll (1992), Villa y Mahieu (1991), White (1992), Sauer (1998), Botella y Alemán (1998) y Botella et al. (1999, 2000). Además, debido a la ausencia de material prehistórico en la muestra recuperada, se ha realizado una datación por $\mathrm{C}^{14}$ de uno de los individuos para confirmar la cronología ibérica que evidenciaban los demás materiales.

La identificación taxonómica de los restos de fauna se ha realizado mediante las colecciones de referencia del Gabinete de Fauna Cuaternaria del $\mathrm{Mu}$ seo de Prehistoria de Valencia. Además del grupo de indeterminados, se han creado tres categorías: talla grande, talla media y talla pequeña, donde quedan agrupados aquellos restos de imposible determinación específica pero con características apreciables. El número de restos identificados - NISP- de cada taxón se ha establecido como la primera unidad de cuantificación. Se ha calculado el número mínimo

${ }^{4}$ Viciano, J.: Métodos odontométricos para la estimación del sexo en individuos adultos y subadultos. Tesis doctoral inédita presentada en 2012 en la Univ. de Granada. 

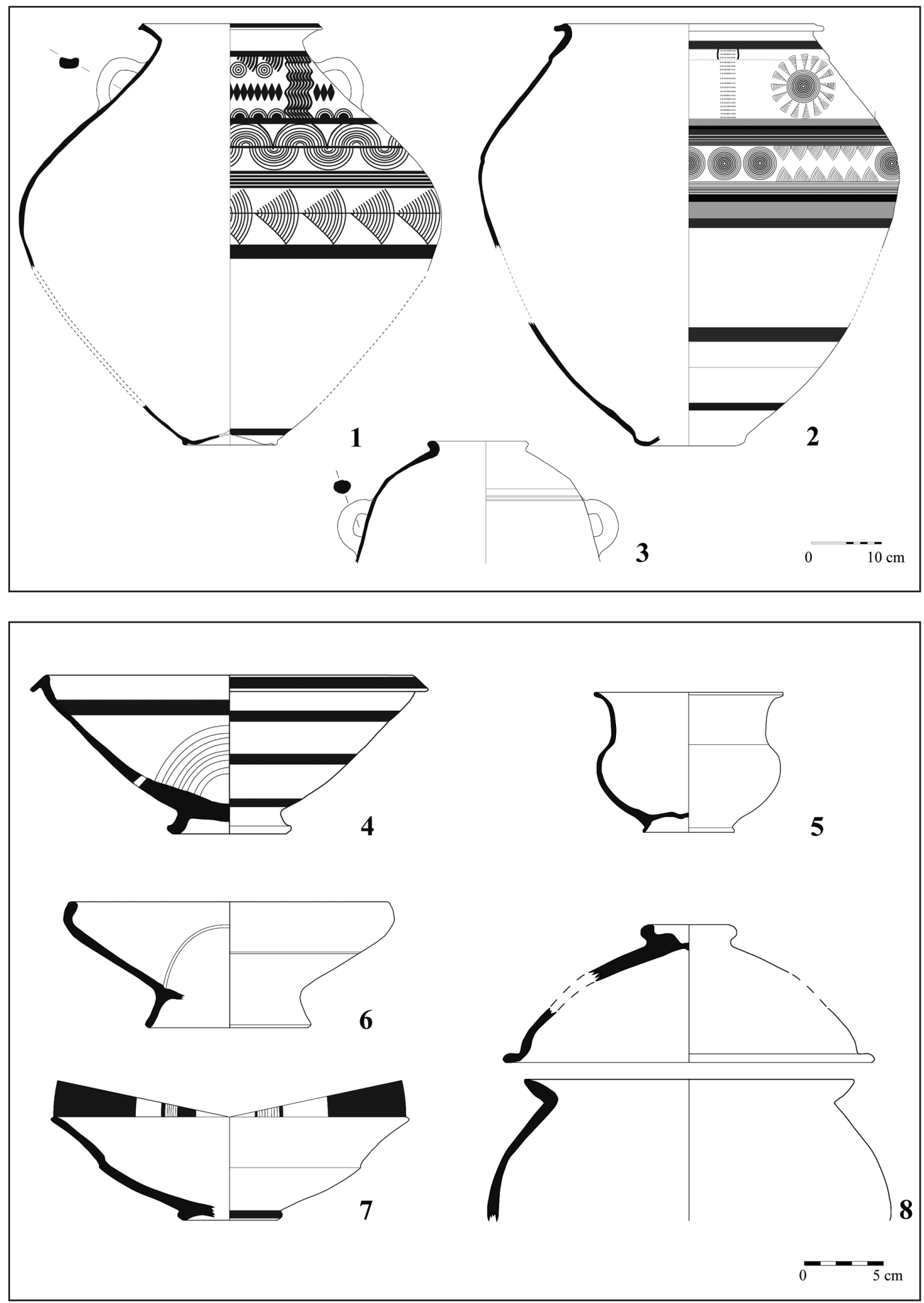

FIG. 3. Recipientes cerámicos más representativos: 1-2) tinajas con decoración geométrica; 3) ánfora; 4) mortero; 5) caliciforme; 6) pátera; 7) plato de ala ancha; 8) olla. 
de elementos esqueléticos $-\mathrm{NME}-$ de cada hueso y el número mínimo de individuos-NMI- (Reitz y Wing, 1999; Lyman, 2008). Los valores de representación anatómica (\%R) se han calculado según Dodson y Wexlar (1979). La edad de muerte se ha establecido teniendo en cuenta las secuencias de erupción y desgaste dental así como el grado de fusión articular (Silver, 1969; Bull y Payne, 1982; Payne, 1982; Mariezkurrena, 1983; Hillson, 1986; Horard-Herbin, 2000; Sanchis, 2012) y se han definido cuatro cohortes: infantiles -dentición decidual en erupción o sin desgaste, elementos no osificados y de pequeño tamaño-, juveniles -con dentición decidual y elementos no fusionados que no han alcanzado el tamaño de adultos-, subadultos -con dentición permanente con nulo o escaso desgaste, parcial fusión articular y talla de adultos-y adultos -con dentición permanente con desgaste y completa fusión articular-. El origen de las fracturas -en fresco o seco- se ha establecido a partir de Villa y Mahieu (1991). Se han caracterizado las modificaciones presentes en los restos, las de origen antrópico -marcas de utensilios y fracturas-, las relacionadas con otros agentes bióticos-mordeduras y huesos digeridos-y las de carácter postdeposicional (Binford, 1981; Pérez Ripoll, 1992; Blasco Sancho, 1992; Lyman, 1994; Iborra, 2004; Sanchis, 2012). Dada la importancia y singularidad de la muestra faunística del yacimiento, su estudio forma parte de un trabajo independiente donde se presentarán los datos de manera más detallada, incluyendo el análisis biométrico 5 . En este estudio, de carácter más general, se describen los aspectos más relevantes del conjunto óseo-especies representadas, edades de muerte, representación esquelética, origen de la fragmentación y modificaciones- que nos permiten definir el origen y funcionalidad de las acumulaciones en la Cueva del Sapo.

\section{Resultados}

\subsection{Material cerámico}

Las cerámicas son, junto con los restos de fauna, uno de los materiales más abundantes de la cueva.

5 Estos y otros aspectos son tratados de forma más detallada en Machause, S. y Sanchis, A.: "La ofrenda de animales como práctica ritual en época ibérica: la Cueva del Sapo (Chiva, Valencia)". En Sanchis, A. y Pascual, L. L. (eds.): Petites preses i grups humans en el passat (II Jornades d'Arqueozoologia, Museu de Prehistòria). Valencia, en prensa.

\begin{tabular}{|c|c|c|c|c|}
\hline Tipo & NMI & Clase & Grupo & Técnica \\
\hline Ánfora & 1 & \multirow{9}{*}{ A } & \multirow{2}{*}{ I } & \multirow{11}{*}{$\mathrm{T}$} \\
\hline Tinaja & 6 & & & \\
\hline Tinajilla & 4 & & II & \\
\hline Caliciforme & 1 & & \multirow{5}{*}{ III } & \\
\hline Plato & 1 & & & \\
\hline Pátera & 4 & & & \\
\hline Escudilla & 2 & & & \\
\hline Cuenco & 1 & & & \\
\hline Mortero & 1 & & $\mathrm{~V}$ & \\
\hline Olla & 4 & \multirow{2}{*}{ B } & & \\
\hline Tapadera & 1 & & & \\
\hline Olla & 3 & & & $\mathrm{M}$ \\
\hline Total & 29 & & & \\
\hline
\end{tabular}

FIG. 4. Material cerámico presente en la Cueva del Sapo: tipo cerámico, número mínimo de individuos (NMI), clase, grupo y técnica (T: a torno; $M$ : a mano).

Los 1145 fragmentos corresponden a un NMI de 29. La mayoría de recipientes son de clase A o cerámica fina $-72 \%-$, mientras que solo el $17 \%$ son de Clase в о cerámica tosca y el $10 \%$ son cerámicas a mano.

El repertorio tipológico es bastante variado, destacando entre las cerámicas de clase A, el grupo I - grandes contenedores destinados al almacenaje y el transporte-, en especial las tinajas -A. I. 2- y el grupo III -vajilla de mesa-, en concreto los platos, páteras y escudillas -A. III. 8-. En las cerámicas de clase $\mathrm{B}$, la variedad tipológica es menor y la forma más representada es la olla -B. 1- (Fig. 4).

Las decoraciones tan solo están presentes en las cerámicas de clase A. Destaca la decoración geométrica, siendo minoritarios los fragmentos con incisiones y motivos florales o vegetales. La mayoría de motivos geométricos son rectilíneos simples -bandas y filetes-, seguidos por los motivos circulares -círculos concéntricos o segmentos de círculo-. Destaca la decoración elaborada y compleja de las dos grandes tinajas, con líneas onduladas y rombos (Fig. 3, n.o 1) y decoración polícroma (Fig. 3, n. ${ }^{\circ}$ 2).

\subsection{Material metálico}

Entre los objetos metálicos se documentan tanto elementos de hierro como de bronce. En hierro 

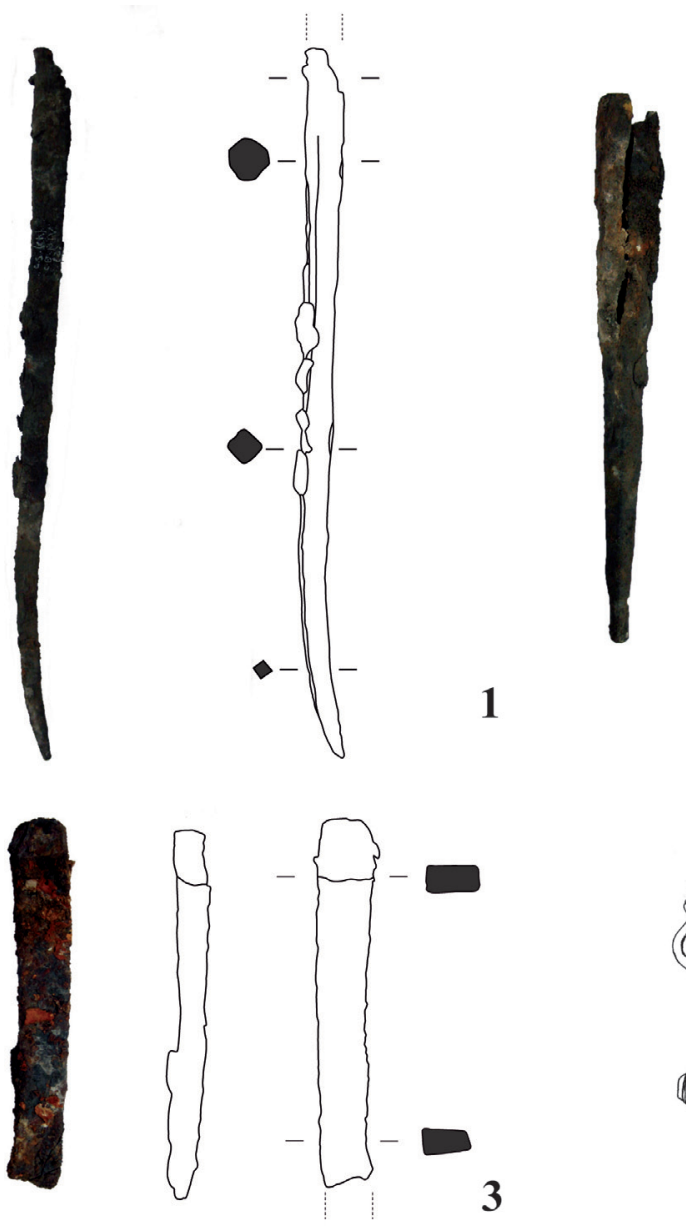

3
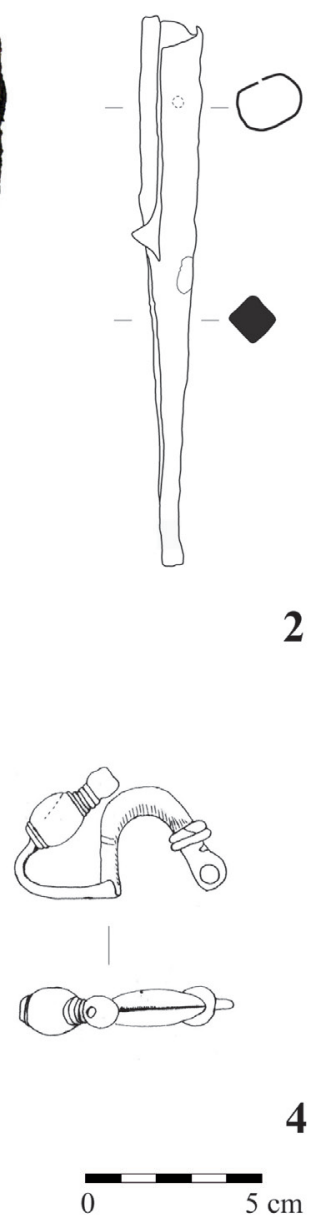

FIG. 5. Algunos objetos metálicos de la cueva: 1) punzón; 2) regatón; 3) cincel; 4) fibula (a partir de Portell, 1983).

encontramos un punzón, un regatón, una varilla y un posible cincel (Fig. 5). Tanto el punzón como el posible cincel presentan evidencias de percusión que demuestran que fueron utilizados repetidamente antes de haber sido depositados en la cueva (Fig. 5, n. ${ }^{\text {os }} 1$ y 3). El regatón es de sección ovalada y cuenta con una abertura longitudinal parcial (Fig. 5, n. ${ }^{\circ}$ 2). Tiene una perforación en el cubo de enmangue para el pasador, que aseguraría la sujeción del astil de la lanza (Quesada, 1997: 427-431).

Entre los elementos de bronce, encontramos elementos claramente ornamentales: dos apliques
2

y una fíbula. Los apliques, ambos de sección rectangular, pudieron servir como refuerzo o elemento decorativo sobre ropa, cajitas o similares, enganchándose a través de sus perforaciones (Grau y Reig, 2002-2003: 115). La fíbula se enmarcaría dentro de las de La Tène I de dos piezas y, en concreto, en el Tipo 3b de Cuadrado (1978) e Iniesta (1983) o grupo iII de Cabré y Morán (1979) (Fig. 5, n. $\left.{ }^{\circ} 4\right)^{6}$. Estas se caracterizan por un pie evolucionado de balaustre, formado por una bola o tonelete, que cuenta con una perforación donde se incrusta una sustancia decorativa, ya sea coral, pasta vítrea, hueso o incluso ámbar (Cuadrado, 1978: 314; Iniesta, 1983: 61). En el caso de la fíbula del Sapo, no sabemos qué tipo de incrustación llevaba ni si se conservaba, ya que no se especifi$\mathrm{ca}$ en el informe. Aunque ha perdido la aguja y el resorte, seguramente se tratara de un resorte bilateral con un muelle que gira a ambos lados de la cabeza, como la mayoría de fíbulas de este tipo.

\subsection{Flora identificada}

Se han analizado un total de 47 fragmentos de carbón, entre los que se han identificado los siguientes taxones: Ficus carica-higuera-, Fabaceae -de la familia de la genista-, Monocotiledónea -de la familia del palmito-, Pinus halepensis -pino carrasco-, Pinus sp., Quercus sp. perennifolio -carrasca, coscoja-, Quercus sp., Rosmarinus officinalis -romero-, Labiatae, además de un fragmento catalogado como indeterminable por su mala conservación (Fig. 6). Exceptuando este último fragmento, el resto de materiales cuenta con un buen estado de conservación, por lo que a excepción de la existencia de algunas hifas y bacterias,

6 Desgraciadamente no podemos aportar más información sobre esta fíbula, ya que se encuentra en paradero desconocido, pero incluimos aquí una imagen del dibujo recogido en el informe inédito de E. Portell: op. cit. n. 3. 


\begin{tabular}{|c|c|c|c|c|c|c|c|c|c|c|}
\hline Taxones & $\begin{array}{c}\text { MUESTRA } \\
1\end{array}$ & $\begin{array}{l}\text { MUESTRA } \\
2\end{array}$ & $\begin{array}{c}\text { MUESTRA } \\
\mathbf{3}\end{array}$ & $\begin{array}{c}\text { MUESTRA } \\
4\end{array}$ & $\begin{array}{l}\text { MUESTRA } \\
\mathbf{5}\end{array}$ & $\begin{array}{c}\text { MUESTRA } \\
6\end{array}$ & $\begin{array}{c}\text { MUESTRA } \\
7\end{array}$ & $\begin{array}{c}\text { MUESTRA } \\
\mathbf{8}\end{array}$ & $\begin{array}{c}\text { MUESTRA } \\
9\end{array}$ & Total \\
\hline Ficus carica & & & 1 & & 2 & & & & 3 & 6 \\
\hline Fabaceae & 10 & & & & & & & & & 10 \\
\hline $\begin{array}{l}\text { Monocotiledónea tp. } \\
\text { Chamaerops humilis }\end{array}$ & & & & & 3 & & & & & 3 \\
\hline Pinus halepensis & & & 2 & 1 & & 5 & & & & 8 \\
\hline Pinus sp. & & 1 & & & & & & & & 1 \\
\hline Quercus perennifolio & & 3 & & & & & 10 & 1 & & 14 \\
\hline Quercus sp. & & 1 & & & & & & & & 1 \\
\hline $\begin{array}{l}\text { Rosmarinus } \\
\text { officinalis }\end{array}$ & & & & & 1 & 1 & & & & 2 \\
\hline Indeterminable & & 1 & & & & & & & & 1 \\
\hline Labiatae & & & & & & & & 1 & & 1 \\
\hline $\begin{array}{l}\text { TOTAL FRAGMENTOS } \\
\text { ANALIZADOS }\end{array}$ & 10 & 6 & 3 & 1 & 6 & 6 & 10 & 2 & 3 & 47 \\
\hline
\end{tabular}

Fig. 6. Frecuencia de los taxones identificados en el análisis antracológico de la Cueva del Sapo.

el carbón muestra pocos signos de estar contaminado (Fig. 7). Algunos fragmentos de Quercus sp. perennifolio reflejan el fenómeno de vitrificación, es decir, la fusión de células vegetales que producen una deformación de su aspecto original. Esta alteración anatómica se explica por la confluencia de diversos factores pre- y postdeposicionales, sin que tenga una correlación directa con la temperatura alcanzada por el fuego (McParland et al., 2010).

\subsection{Restos humanos}

La muestra se compone de 75 fragmentos, de los cuales tres son esquirlas óseas. Entre los restos identificados, 11 son dientes, 20 son huesos del cráneo y 41 del resto del esqueleto. No están representadas todas las unidades anatómicas, con ausencia de maxilar, costillas, cúbito, coxal, sacro, tibia y peroné. El mayor porcentaje de restos analizados corresponde al cráneo -24\%-, seguido de los huesos del pie $-17,33 \%$-, dientes $-14,66 \%-$, huesos de la mano $-13,33 \%-$ y fragmentos escapulares -9,3\%-. El estado de conservación del material es variable, ya que la mayoría de los fragmentos presenta fracturas post mortem y pérdidas óseas. Los elementos completos son en su mayoría los huesos del pie y de la mano, así como los dientes. El grado de preservación de la superficie externa del hueso es bastante bueno, ya que gran parte presenta una superficie intacta y bien conservada.

Se ha estimado un NMI de 2 a partir de los elementos esqueléticos más representativos -mandíbulas y fémures-. Los individuos se han numerado como I y II, en función del sexo estimado. Los indicadores morfológicos en el cráneo (Ferembach et al., 1980) han permitido identificar el individuo I como una mujer. A partir de las dimensiones de los huesos largos (Alemán et al., 1997) se ha estimado el individuo II como un varón (en base a un radio izquierdo). La edad de muerte en el individuo I se valoró teniendo en consideración el estado de las suturas craneales (Meindl y Lovejoy, 1985), completamente abiertas y sin ninguna evidencia de cierre en la tabla externa del cráneo, por lo que se trata de un individuo adulto joven; el grado de fusión de las epífisis de los huesos largos (Brothwell, 1987) del individuo II corresponde con un adulto joven.

En cuanto a los factores tafonómicos que actuaron sobre el conjunto de restos humanos, se han observado modificaciones relacionadas con pequeńos roedores (Botella et al., 1999) sobre un radio 

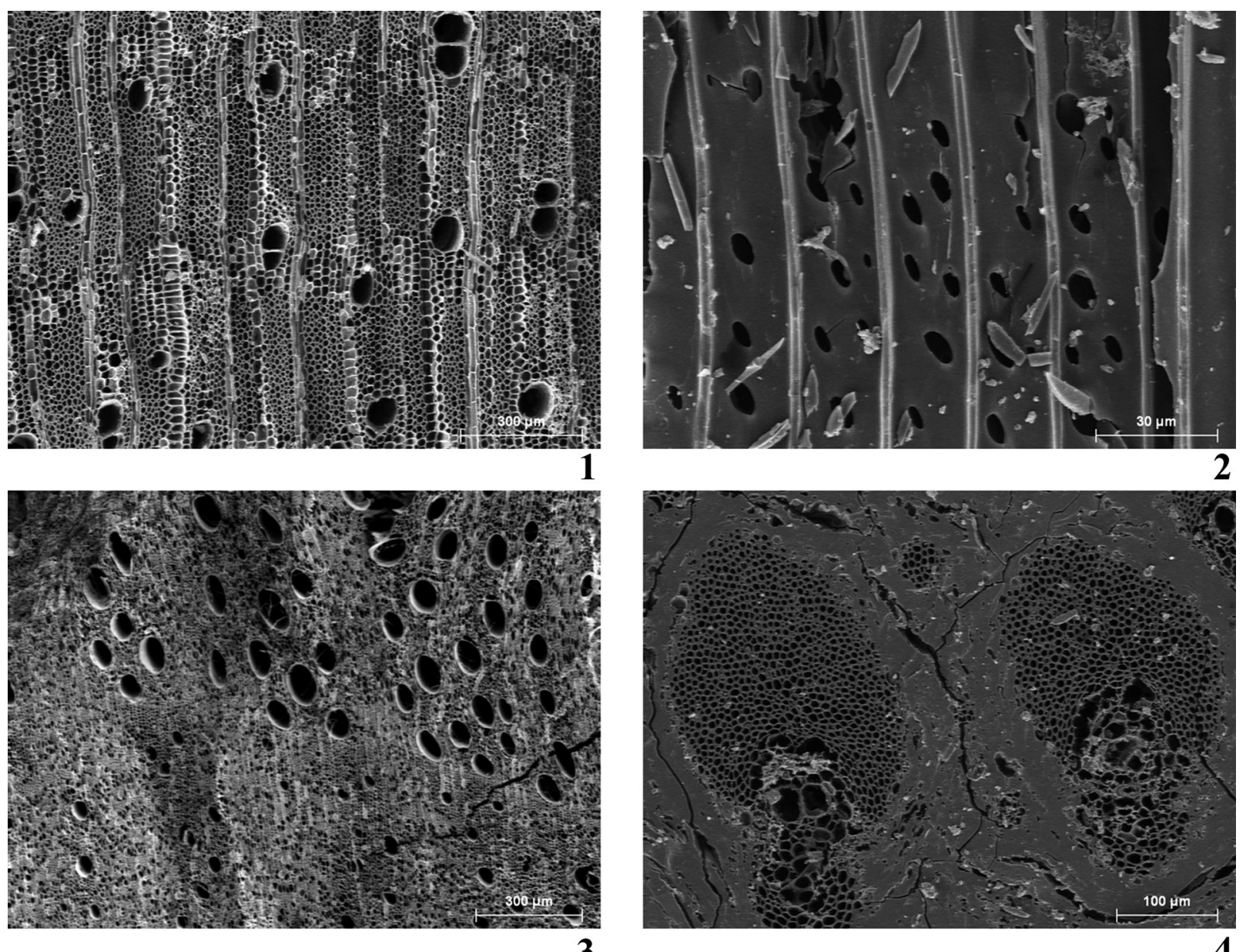

Fig. 7. Fotografías en el microscopio electrónico de algunos de los taxones identificados en la Cueva del Sapo: 1. Ficus carica, plano transversal, X90; 2. Pinus halepensis, plano radial, X800; 3. Quercus sp. perennifolio, plano transversal, X70; 4. Monocotiledónea tp. Chamaerops humilis, plano transversal, X200.

izquierdo. En cuatro fragmentos óseos -el 5,3\% del total de la muestra- se ha identificado la presencia de marcas de corte o incisiones poco profundas, realizadas con un instrumento afilado de manera intencional (Botella et al., 1999) (Fig. 8). Estas modificaciones se registraron en ambos individuos. La asociación de las marcas de corte con un tipo de instrumento determinado -útil metálico o lítico- ha sido imposible de realizar bajo la observación macroscópica. Futuros análisis de la sección transversal de la superficie de corte, con la utilización de un microscopio de barrido electrónico y la realización de réplicas de las marcas, permitirán tal discriminación.
El primer fragmento corresponde a una porción izquierda de calota craneal, perteneciente al individuo I. En la cara externa del parietal se observan cinco grupos de incisiones lineales, dispuestas longitudinal y transversalmente. Presentan una longitud variable, en general de pequeño tamaño, muy finas y de sección en 'v' (Fig. 8, n. ${ }^{\text {os }} 1$ y 5). Según su morfología y distribución, y debido a que en el cráneo existe poca masa muscular, se relacionan con el corte de la piel y del músculo temporo-parietal del individuo.

El segundo fragmento óseo con marcas de corte es un radio izquierdo perteneciente al individuo II. En el tercio distal de la diáfisis y en su cara anterior, 

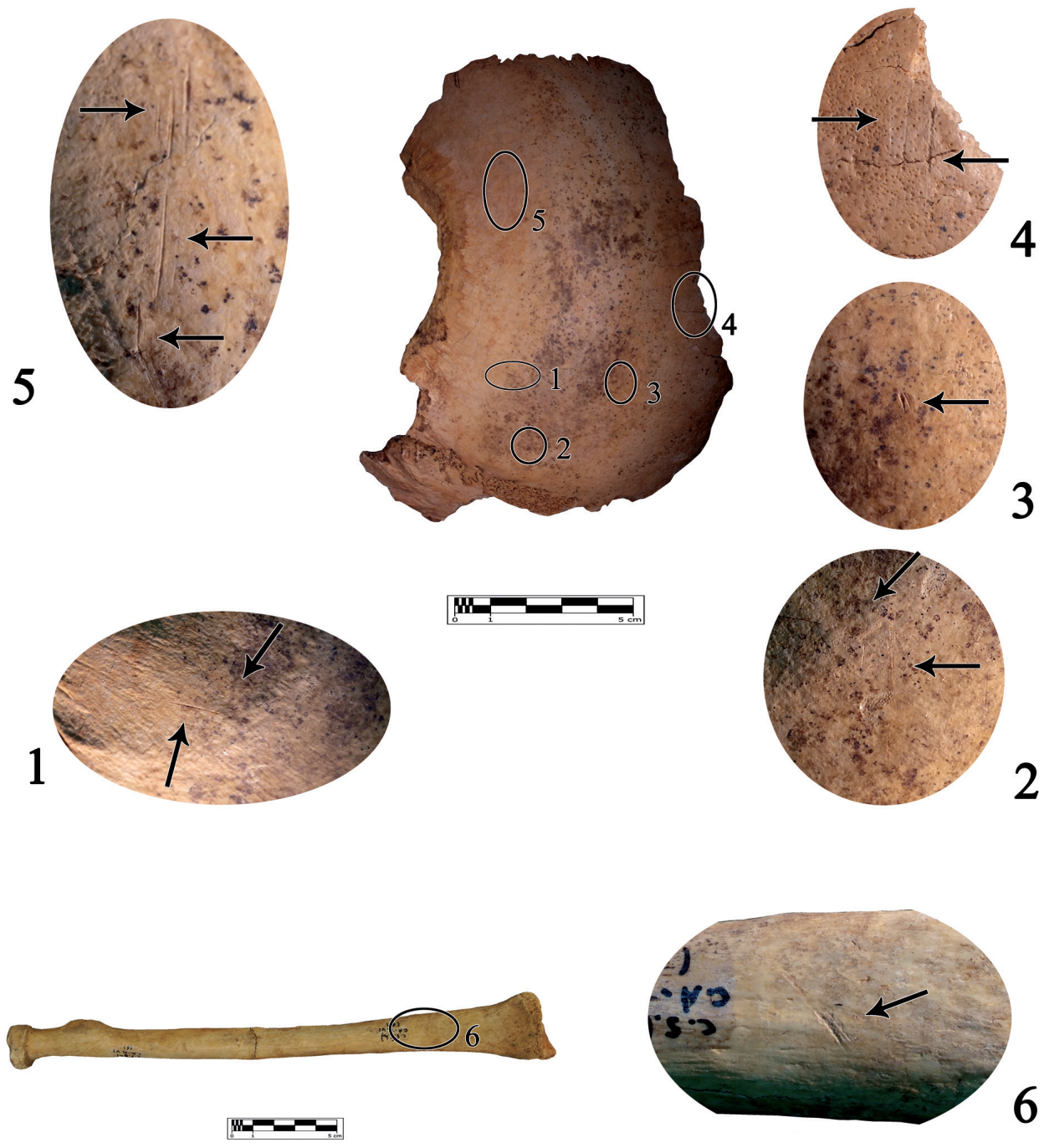

파무음

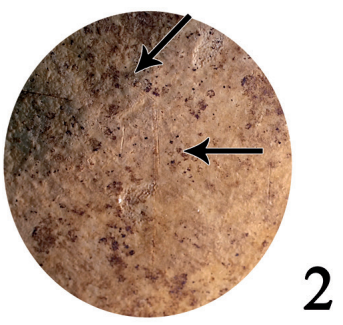

2
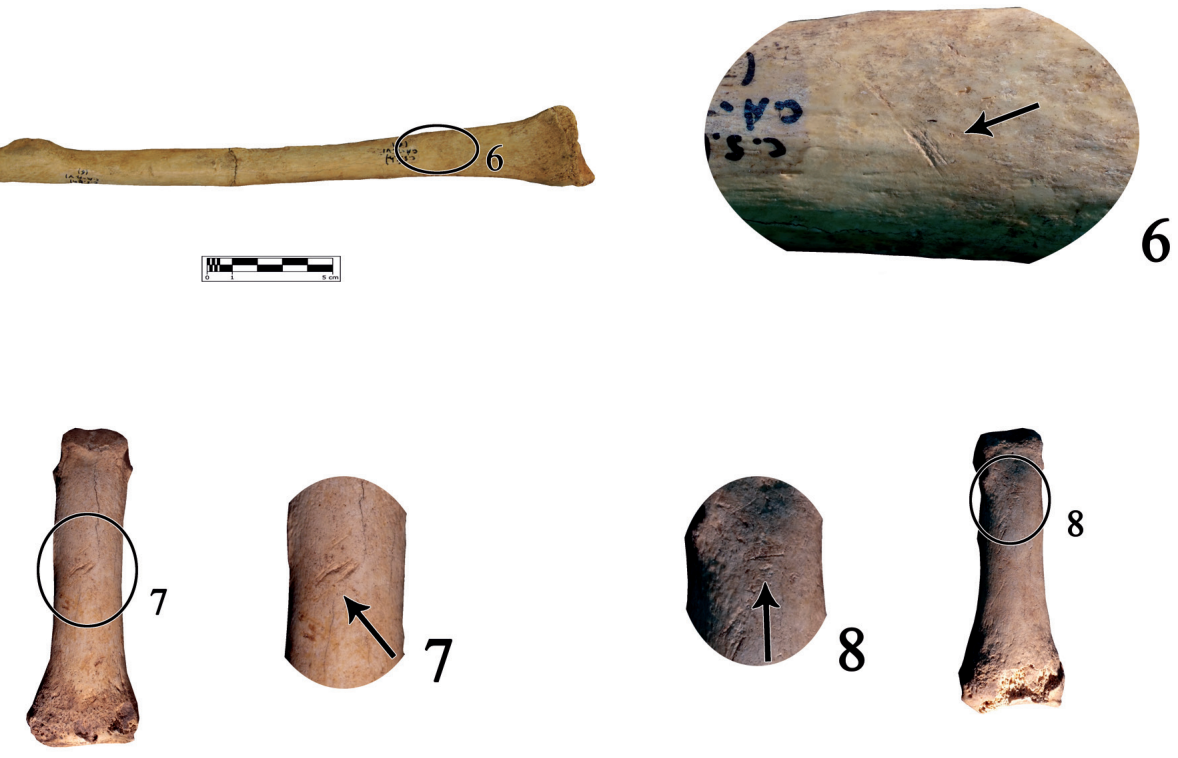

Pram

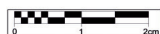

Fig. 8. Restos humanos de la Cueva del Sapo con marcas de corte sobre el hueso: 1-5. Incisiones observadas en porción izquierda de calota craneal; 6. Grupo de incisiones en radio izquierdo; 7. Marcas de corte en falange medial izquierda; 8. Marcas de corte en falange proximal izquierda. 


\begin{tabular}{|c|c|c|c|c|}
\hline TAXones & NISP & $\%$ NISP & NME & NMI \\
\hline Bos taurus & 2 & 0,13 & 1 & 1 \\
\hline Capra hircus & 15 & 0,99 & 15 & 3 \\
\hline Capra sp. & 4 & 0,26 & 4 & 2 \\
\hline Ovis aries & 17 & 1 & 17 & 2 \\
\hline Ovicaprino indet. & 224 & 14,72 & 184 & 7 \\
\hline Sus sp. & 2 & 0,13 & 2 & 2 \\
\hline Canis familiaris & 17 & 1 & 17 & 2 \\
\hline Canis sp. & 23 & 1,51 & 21 & 2 \\
\hline Total domésticos & 304 & 19,98 & 261 & 21 \\
\hline Cervus elaphus & 809 & 53,15 & 536 & 12 \\
\hline Capreolus capreolus & 1 & 7 & 1 & 1 \\
\hline Capra pyrenaica & 1 & 7 & 1 & 1 \\
\hline Oryctolagus cuniculus & 69 & 4,53 & 65 & 5 \\
\hline Lepus sp. & 9 & 0,59 & 9 & 2 \\
\hline Leporidae & 3 & 0,2 & 3 & 2 \\
\hline Bufo sp. & 1 & 7 & 1 & 1 \\
\hline Lacerta lepida & 8 & 0,53 & 7 & 2 \\
\hline Ophidia & 6 & 0,39 & 6 & 1 \\
\hline Alectoris rufa & 2 & 0,13 & 2 & 1 \\
\hline Columba palumbus & 1 & 7 & 1 & 1 \\
\hline Columba sp. & 9 & 0,59 & 9 & 2 \\
\hline Pyrrhocorax sp. & 36 & 2,37 & 35 & 5 \\
\hline Ave indet. & 120 & 7,88 & 119 & 3 \\
\hline Apodemus silvaticus & 1 & 7 & 1 & 1 \\
\hline Myotis sp. & 1 & 7 & 1 & 1 \\
\hline Quiroptera & 13 & 0,85 & 13 & 2 \\
\hline Iberus alonensis & 97 & 6,37 & 97 & 97 \\
\hline Sphincterochila candidissima & 2 & 0,13 & 2 & 2 \\
\hline Pseudotachea splendida & 4 & 0,26 & 4 & 4 \\
\hline Rumina decollata & 21 & 1,38 & 21 & 21 \\
\hline Theba pisana & 4 & 0,26 & 4 & 4 \\
\hline Total silvestres & 1218 & 80,02 & 938 & 171 \\
\hline Total & 1522 & 100 & 1199 & 192 \\
\hline
\end{tabular}

Fig. 9. Especies de fauna identificadas en la Cueva del Sapo según NISP, \%NISP, NME y NMI. se observan dos incisiones oblicuas y paralelas, muy próximas entre sí y con sección en ' $v$ '. Estas incisiones debieron cortar el músculo flexor largo del dedo pulgar (Fig. 8, n. ${ }^{\circ}$ 6).

El tercer fragmento es una falange medial de la mano izquierda. En la norma palmar, se observan dos grupos de incisiones oblicuas y paralelas, muy próximas entre sí. Según su localización, estos cortes debieron seccionar el tendón perforante del músculo flexor superficial de los dedos (Fig. 8, n. ${ }^{\circ} 7$ ).

El cuarto fragmento corresponde a una falange proximal de la mano izquierda. En su norma dorsal presenta dos grupos de incisiones, con sección en 'v' y profundidad variable. La localización de estos cortes sugiere que debieron seccionar el tendón del músculo extensor de los dedos (Fig. 8, n. ${ }^{\circ} 8$ ).

\subsection{Restos de fauna}

La muestra de fauna estudiada asciende a un total de 4392 restos, de los cuales se han podido identificar $1522-34,65 \%-$. Los restantes 2870 no identificados representan el $65,35 \%$ del total y se han dividido en varios grupos: taxones de talla pequeña -NR: $31 ; 0,71 \%-$, de talla media -NR: 2582; $58,79 \%-$, de talla grande -NR: 5; 0,11\%- y fragmentos indeterminados -NR: 252; 5,74\%-. Los determinados corresponden a 30 especies distintas, con presencia de ungulados silvestres y domésticos, lepóridos, anfibios, reptiles, micromamíferos, aves y gasterópodos.

La especie mejor representada en la muestra -sin considerar a los gasterópodos- es el ciervo, tanto en NISP $-53,15 \%$ - como en NMI $-12-$. En segundo lugar se encuentra el grupo formado por ovejas -NMI 2-, cabras -NMI 2-3-y ovicaprinos indeterminados -NMI 7-, que representa el 17,09\% del NisP. Otros animales domésticos son el bovino -NMI 1-, el cerdo -NMI 2-y el perro, este último con diversos restos de al menos dos individuos. Entre los silvestres, los lepóridos, básicamente conejos, alcanzan el 5,32\% del NISP y nueve individuos; las aves están representadas por tres especies - perdices, palomas y sobre todo chovas- con el 11,04\% del NISP y 12 individuos; los gasterópodos aparecen en la muestra con diversas especies continentales $-8,14 \%$ del Nisp y 128 individuos-. También se 
documentan, aunque con valores muy modestos, la cabra montés, el corzo, micromamíferos, reptiles y anfibios (Fig. 9).

En relación a la estructura de edad de las principales especies, el ciervo está presente en la muestra con 12 individuos, la mitad son adultos de más de tres años, uno de los cuales llegó a una edad avanzada. Los restantes seis individuos se reparten entre cuatro infantiles de menos de 1 ańo y dos jóvenes de 1 a 2 años. Los ovicaprinos indeterminados corresponden a siete individuos diferentes, con dos adultos, tres subadultos, un individuo joven y otro infantil. Las dos ovejas determinadas son un ejemplar joven de menos de 1 año y otro adulto de más de 3 años que podrían corresponder a alguno de los ovicaprinos indeterminados. Lo mismo podríamos decir de los tres individuos de cabra, dos de ellos jóvenes - menos de 1 año-y el otro un subadulto o adulto -más de 1 año-.

Los diversos elementos anatómicos aparecen representados tanto en ciervos como en ovicaprinos, si bien con distintas frecuencias. En general destacan los huesos de los miembros mientras que los del cráneo y esqueleto axial muestran valores escasos. Por el momento no sabemos si esto se debe a un problema de conservación diferencial.

Una de las características más destacadas, tanto en ciervos como en ovicaprinos y que también podemos hacer extensible a las otras especies, es la importancia de restos completos y por tanto el relativo bajo nivel de fragmentación de la muestra - NME/ $\mathrm{NR}=0,78-$. El 60\% de los restos de ciervo y el 75\% de los de ovicaprinos se conservan completos. Aunque una gran parte de las fracturas son de origen indeterminado, se han podido identificar aquellas de origen arqueológico. Por ejemplo, en los ciervos casi el $70 \%$ de las fracturas son postdeposicionales $y \tan$ solo un $30 \%$ se han originado en fresco. En el caso de los ovicaprinos, la mitad se han producido en fresco y la otra mitad en seco.

Algunos restos óseos comportan modificaciones de origen humano $-5,5 \%$ del NISP- así como otras evidencias relacionadas con la acción de otros agentes bióticos $-3,6 \%-$ y que se han originado antes del enterramiento de los restos. Del mismo modo, se han detectado diversas modificaciones de tipo postdeposicional -10,3\%-. Aquellas causadas por los humanos se muestran sobre 85 restos, la mayoría de ciervo -65-, aunque también se documentan sobre huesos de ovicaprino -12-, perro y cánido indeterminado -7- y conejo -3-. En los ciervos estas evidencias se corresponden con marcas de corte producidas por útiles $-52-$, termoalteraciones $-11-$ y huesos trabajados -2-. En los ovicaprinos -12-, aparecen huesos quemados $-7-$ y marcas de corte -5-. La localización de las marcas en los restos de ciervo muestra diversas fases del procesado carnicero que podrían corresponder tanto al pelado, como a la desarticulación o también, en algunos casos, al descarnado/consumo. En el caso de los ovicaprinos, los restos identificados presentan escasas evidencias de marcas de corte, lo cual también es muy significativo, aunque nos impide realizar cualquier valoración sobre su funcionalidad. En el caso de los restos de perros y cánidos indeterminados, destacan las marcas sobre metapodios y extremos de huesos largos que parecen relacionarse con el pelado y la desarticulación, pero no con el descarnado/consumo ${ }^{7}$.

Las evidencias no antrópicas aparecen sobre 49 restos y se han originado por mordeduras, roeduras -acción dental- y procesos digestivos que relacionamos con la actividad de carnívoros y roedores. La mayoría aparecen en huesos de ciervo -48,21\%-, conejo $-32,14 \%-$ y ovicaprinos $-33,33 \%-$. Encontramos todo tipo de alteraciones producidas por la acción de agentes bióticos no antrópicos, entre los que destacan en número los arrastres, las punciones y las horadaciones, fundamentalmente sobre los huesos de conejo. Algunos restos de ciervo y de ovicaprinos pueden ser consecuencia del carroñeo ejercido por perros o zorros sobre conjuntos originados por los humanos, ya que dos huesos de ciervo presentan una combinación de marcas de corte y mordeduras, mientras que los restos de conejo y de otros pequeños animales se vinculan al aporte de carnívoros, con presencia de huesos mordidos y digeridos de características similares a los documentados en referentes actuales de zorro (Sanchis, 2012).

La mayoría de modificaciones postdeposicionales se localizan sobre restos de ciervo -66,46\%-, ovicaprinos $-11,39 \%$ - y conejo -8,86\%-. Entre este tipo de alteraciones producidas tras el enterramiento de los restos destacan las manchas producidas por el óxido de manganeso y las alteraciones estructurales producidas por la meteorización -grietas, desescamación, etc.-.

7 Cf. n. 5. 


\section{Cronología}

La cultura material recuperada hasta la fecha se relaciona principalmente con un uso ibérico de la cavidad. El volumen de materiales nos muestra que la cueva fue utilizada tan solo en determinados momentos específicos, siendo seguramente el periodo entre los ss. V-IV a. C. el de mayor frecuentación.

El s. v- inicios del s. Iv a. C. aparece representado en la cueva por la gran tinaja con decoración polícroma (Fig. 3, n.o 2), un plato de ala ancha (Fig. 3 , n. ${ }^{\circ}$ 7) y un mortero de labio saliente y pendiente (Fig. 3, n. ${ }^{\circ}$ 4). Aunque la mayoría de motivos geométricos aparecen a lo largo del s. v, es a partir del s. IV cuando comienzan a utilizarse nuevos motivos como los meandros que vemos representados en una de las grandes tinajas (Fig. 3, n. ${ }^{\circ} 1$ ). Además, la fíbula de bronce de la Tène I (Fig. 5 , n. ${ }^{\circ} 4$ ), similar a algunas de las que aparecen en la necrópolis del Cigarralejo de Mula, nos da una datación del 400-350 a. C. (Cuadrado, 1987: figs. 79, 120 y 258; Cabré y Morán, 1982).

Asimismo, se realizaron dataciones radiocarbónicas por Aceleración de Espectrometría de Masas - AMs $^{8}{ }^{8}$. La muestra seleccionada fue tomada de un fragmento de hemimandíbula izquierda del individuo I. El resultado proporcionó la fecha de $2230 \pm$ $30 \mathrm{BP}$, que calibrada $2 \sigma$ ofrece la horquilla cronológica de 2340-2150 cal вр (390-200 cal вс).

El s. III a. C. aparece representado en la cueva por las páteras de pie alto (Fig. 3, n. ${ }^{\circ}$ 6) y los fragmentos de decoración floral, entre los que destacamos una hoja cordiforme, un capullo y dos posibles evidencias de decoración figurada: un zapatero y una pata de animal.

\section{Discusión}

A la hora de interpretar los datos extraídos, debemos tener en cuenta las limitaciones intrínsecas del conjunto. En primer lugar, estudiamos unos materiales que proceden de una donación, así como de una intervención de urgencia inacabada. En segundo lugar, los numerosos expolios producidos han distorsionado en gran medida su registro arqueológico

8 Datación por radiocarbono realizada en el Beta Analytic Inc. (Miami, Florida, EE. UU.): AMs-Standard. INTCAL09 Database. y sedimentológico. Teniendo en cuenta todos estos factores, que dificultan la comprensión de un contexto ya de por sí complicado -al existir una remoción natural de tierras-, abordaremos a continuación su posible significado.

Las pocas referencias que se han hecho sobre la Cueva del Sapo han dado interpretaciones muy diversas. E. Portell opinaba que no se podía incluir dentro del conjunto de cuevas-santuario ni cuevas-refugio, tal y como habían sido definidas por M. Gil-Mascarell (1975), pero tampoco podía asegurar que fuera una cueva funeraria (Portell, 1983). I. Sarrión la interpreta como una cueva de habitación o necrópolis (Sarrión, 1990). Mientras que otros, como T. Moneo (2003) y J. GonzálezAlcalde (2011), la relacionan más bien con una actividad ritual.

Las investigaciones realizadas hasta el momento sobre cuevas con vestigios ibéricos planteaban dos posibles interpretaciones: que fuera un lugar de frecuentación esporádica -cueva-refugio- o bien un espacio de uso ritual -cueva-santuario-. Si nos basamos en los criterios tradicionales establecidos por M. Gil-Mascarell (1975), la primera opción queda descartada. El volumen de materiales no se corresponde con el que se ha relacionado con las cuevas de este tipo y, además, sus características topográficas dificultan la habitabilidad dentro de la misma. Por otra parte, la Cueva del Sapo no cuenta con los trazados laberínticos que se han relacionado excesivamente con las cuevas-santuario (Gil-Mascarell, 1975), pero aun así, presenta una importante pendiente, un espacio interno estrecho pero de gran altura y unos fenómenos kársticos que le otorgan una atmósfera a tener en cuenta en el contexto de un acto ritual.

Si valoramos los materiales cerámicos hallados, observamos que gran parte de ellos podrían relacionarse con una actividad ritual. Aunque tradicionalmente se suele otorgar una excesiva correlación entre la presencia de los vasos caliciformes y la ritualidad de las cuevas con materiales ibéricos, pensamos que estos vasos no pueden ser considerados como única evidencia de actividad ritual. En la Cueva del Sapo, tan solo existe un vaso de este tipo, pero las actividades rituales que implicarían el uso de recipientes cerámicos pudieron llevarse a cabo con otros elementos, como platos, páteras o tinajillas, como se indicó por ejemplo en el caso de 
la Cova de les Encantades de Montcabrer (Coll et al., 1994: 62). Asimismo, es posible que todos estos recipientes se depositaran en la cueva como ofrendas en sí mismas y no como simples contenedores. Además, cabe destacar la presencia de grandes recipientes como el ánfora o las dos tinajas decoradas, que tradicionalmente no se han relacionado directamente con el culto en las cuevas-santuario, pero seguramente formaron parte de los rituales desarrollados en la Cueva del Sapo. Otros elementos como el mortero, un recipiente poco representado dentro del repertorio de cerámica ibérica en los poblados, pudo estar destinado al machacado de sustancias aromáticas, relacionándose posiblemente con la bebida de vino aromatizado, según se ha propuesto para otros contextos culturales (Vives-Ferrándiz, 2004; Curé, 2010). Por otro lado, los elementos de adorno con decoraciones cuidadas como la fíbula también pudieron ser parte de las ofrendas realizadas en la cueva.

El análisis antracológico de este yacimiento proporciona unos datos ecológicos interesantes para su ubicación biogeográfica y, por tanto, su interpretación paleoecológica. La presencia de taxones termófilos como la higuera o el palmito, junto a elementos del matorral esclerófilo mediterráneo -romero, leguminosas, coscoja-, permite ubicar la Cueva del Sapo en el piso bioclimático termomediterráneo -temperaturas medias anuales de 17-19 ${ }^{\circ} \mathrm{C}-$. Estos datos, coherentes con la imagen de la vegetación actual del entorno de la Sierra de Chiva (Rivas-Martínez, 1987), evidencian una serie de aportes intencionales de leña con el objetivo de realizar fuegos. Aunque la escasez de muestras dentro del conjunto de materiales y la ausencia de áreas de actividades bien definidas dentro del yacimiento nos impide conocer la función de estos fuegos - utilitaria o ritual-, sí sabemos que la madera recolectada para ello procedería del entorno más inmediato.

El conjunto de materiales de la Cueva del Sapo difiere del que encontramos en otras cuevas que han sido relacionadas con actos rituales. La cerámica no muestra grandes concentraciones, tal y como ocurre por ejemplo con los más de 100 vasos caliciformes de una de las cuevas del Puntal del Horno Ciego de Villagordo del Cabriel (Martí Bonafé, 1990), con el elevado número de ollas de la Cova dels Pilars de Agres (Grau, 1996, 2000; Grau y Olmos, 2005) o con la ofrenda de más de 200 fusayolas de la Cueva de Cerro Hueco de Requena (Martínez Valle y Castellano, 1996). Pero sí que presenta una concentración de restos de fauna, donde predomina el ciervo, lo que resulta inusual en otros contextos de hábitat del mundo ibérico donde las especies domésticas son siempre las mejor representadas. Aunque el yacimiento se sitúa en un entorno óptimo para las especies silvestres, el predominio de ciervos en la cueva indica que existió una caza intencionada previa a su depósito.

El problema es que tan solo contamos con dos estudios de fauna para contextos similares en la zona en cuestión: la Cueva in del Puntal del Horno Ciego en Villagordo del Cabriel (Sarrión, 1990) y la Cueva Merinel en Bugarra (Blay, 1992), ambos con características diferentes a las de la Cueva del Sapo. En el primer caso, I. Sarrión realizó básicamente un listado taxonómico de especies, entre las cuales determinó algunos restos con alteraciones antrópicas -ciervos y suidos- y vinculó la mayoría de aportes de pequeños animales con poblaciones naturales. En el segundo ejemplo, F. Blay identificó un patrón relacionado directamente con una actividad ritual en la que existía una selección de edades y partes del cuerpo -ya que se depositaron restos craneales de infantiles y neonatos- y una selección de especies, como ocurre en la Cueva del Sapo. Aun así, en este caso se trataba de animales domésticos, principalmente ovicaprinos y suidos, como ocurre en otras cuevas con evidencias rituales de la zona actual de provincia de Castellón (Oliver Foix, 2010). Difiere también del que se documenta entre los desperdicios domésticos de los poblados (Iborra, 2004) e incluso en los depósitos fundacionales o rituales en contextos de hábitat (Barrial, 1990; Méniel, 1992; Belarte y Sanmartí, 1997; Albizuri, 2011, entre otros). Frente al predominio de especies domésticas que encontramos en los poblados, el registro de la Cueva del Sapo se caracteriza por la abundancia de restos de ciervo y la presencia de marcas de corte sobre especies que no suelen ser consumidas en los poblados, como por ejemplo el perro (Iborra, 2004: 363). Además, parece que el tratamiento dado a los animales es diferente al de los contextos domésticos, ya que la muestra presenta una baja fragmentación y la frecuencia de marcas de corte es muy limitada $-2-6 \%$ si tenemos en cuenta los ovicaprinos y ciervos, que son las especies más representativas-. Estos datos son muy diferentes a los que encontramos en 
contextos de hábitat de una cronología similar, con marcas de corte presentes en el 20-30\% de los restos, dependiendo de yacimientos y especies (Iborra, 2004: 135-139, 177-188).

En los rituales generalmente se ofrece a la divinidad, ya sea a través del fuego o de una ofrenda, aquello que es valioso para el grupo de personas que realizan el acto cultual: una copa de importación griega, un exvoto, una cerámica ibérica o, en este caso en concreto, un animal valioso para el grupo como pudo ser el ciervo. Su significado simbólico en un momento o espacio determinado dependerá, sin embargo, de la manera en que se deposite o se utilice (López-Bertran y Vives-Ferrándiz, 2009: 181).

En la Cueva del Sapo, el ritual en el que participarían estos animales consistiría en depositarlos tras su inmolación, lo que explicaría el procesado parcial no vinculado al consumo y el tratamiento diferenciado de los animales cazados -ciervos-, frente a los animales que suelen ser sacrificados en otros contextos -ovicaprinos-. Las ofrendas cárnicas de animales salvajes no son muy comunes, ni en el mundo ibérico ni en otras culturas coetáneas. $\mathrm{Y}$, de hecho, cuando aparecen estos restos en contextos de la Edad del Hierro, como por ejemplo en el santuario galo de Gournay-sur-Aronde en el N de Francia, suelen interpretarse como trofeos (Méniel, 2012). Por lo tanto, pensamos que tiene cierto sentido que, en una ofrenda sin interés cárnico, sea mucho más preciada una especie salvaje que una doméstica, ya que para su consecución es necesaria la caza (Colominas, 2008). Así pues, en el caso de la Cueva del Sapo, el valor simbólico no vendría del alimento en sí, sino de la renuncia a un animal como el ciervo, y posiblemente su caza (Cabrera, 2010). De hecho, seguramente esta actividad estuviera en conexión directa con los rituales realizados en la cueva, ya que, como nos demuestran las fuentes clásicas y la iconografía ibérica, ciertas actividades cinegéticas se relacionarían con un determinado rol social y simbólico entre los iberos (Aranegui et al., 1997). Formando parte de ceremonias de iniciación en las que el joven accedería a los límites del territorio del oppidum para superar diversas pruebas y poder así reintegrarse como adulto en la estructura social (Olmos y Grau, 2005). Aunque desconocemos los protagonistas que tomaron parte en el ritual relacionado con la caza del ciervo en la Cueva del Sapo, es posible que estuviera vinculado a determinados grupos de género y/o edad.

Por otra parte, el análisis de los restos humanos ha evidenciado un depósito secundario con la presencia de dos individuos, uno femenino y otro masculino, ambos adultos jóvenes. Las incisiones que presentan algunos de los fragmentos óseos, realizadas en el perimortem y de manera intencional, indican la existencia de un complejo ritual funerario. Siguiendo la clasificación propuesta por Binford (1989), Pérez Ripoll (1992) y Botella et al. (1999, 2000), estas marcas reflejan acciones muy similares a las empleadas en el procesado de los animales. La intencionalidad de las incisiones observadas en el cráneo, finas y rectilíneas, de longitud variable, se relaciona con el desollado, es decir, como consecuencia de cortar la piel para separarla del resto del cuerpo. En el cráneo, como la piel está muy próxima al hueso, estas marcas se aprecian de manera muy clara. En las zonas de inserción muscular y ligamentos, como por ejemplo la región temporal, las incisiones son múltiples e irregulares (Botella et al., 1999, 2000). En el caso de las incisiones observadas en el esqueleto postcraneal, tanto en el radio como en las dos falanges, localizadas en la superficie externa de la diáfisis, lineales, dispuestas de forma paralela y en sentido perpendicular y transversal respecto al hueso, se relacionan con el descarne, es decir, con el proceso de extracción de las masas musculares y partes blandas (Botella et al., 1999, 2000).

El significado de estas marcas abarca un amplio abanico de posibilidades: tratamiento ritual del cadáver, actos de muerte violenta, sacrificios humanos, canibalismo, etc., las cuales pueden generar modificaciones similares en el hueso. Sin embargo, el hallazgo de restos humanos con marcas de corte está ampliamente documentado en numerosos lugares de diferentes cronologías (White, 1992; Fernández-Jalvo et al., 1999; Botella et al., 2000; Aura et al., 2010, entre otros), mejorando considerablemente las posibilidades de su estudio. Uno de los criterios más importantes para diferenciar este tipo de conductas es el contexto arqueológico y el tipo de depósito. Los criterios básicos que permiten la identificación del canibalismo vinculados con las modificaciones óseas son muy similares a los que se observan en los conjuntos de fauna originados como consecuencia de la alimentación 
de los grupos humanos: presencia de fracturas en fresco, marcas de corte en el perimortem y de carácter intencional, alteraciones térmicas, mordeduras humanas, señales de percusión, modificaciones del canal medular, golpes, arrancamientos y representación diferencial de elementos esqueléticos. Por lo tanto, el patrón de las marcas debe ser comparable o similar al tratamiento carnicero sobre los huesos de animales.

Las modificaciones antrópicas documentadas sobre los restos humanos de la Cueva del Sapo, básicamente marcas de corte o incisiones en la superficie externa del hueso, no permiten relacionarlas directamente con la práctica del canibalismo, ya que no cumplen todos los parámetros establecidos para la interpretación de esta práctica (Botella y Alemán, 1998). Tampoco se ha documentado la presencia de evidencias típicas como marcas de dientes humanos, cocción o extracción de médula. Tan solo el 5,3\% de los restos presentan este tipo de incisiones, una frecuencia bastante baja en comparación con otras colecciones donde se ha confirmado la existencia de canibalismo, como en yacimientos de la América prehispánica (Turner y Turner, 1999; White, 1992) o en colecciones neolíticas europeas (Botella, 1973; Jiménez et al., 1986; Villa et al., 1986; Villa, 1992; Botella et al., 2000, 2003), entre otras.

Las evidencias arqueológicas que permiten valorar un contexto de agresión y conflicto implican la presencia de armas, restos defensivos, la identificación de una amplia variedad de tipos de lesiones traumáticas, así como representaciones iconográficas (Martin y Frayer, 1997; Walker, 2001). Por lo tanto, los restos de la Cueva del Sapo tampoco pueden ser relacionados con este tipo de contextos de violencia.

Hasta la fecha, los conjuntos ibéricos de restos de individuos adultos inhumados, que presentan un tratamiento funerario diferente a la práctica de la cremación, son generalmente partes craneales que provienen de contextos de hábitat-sobre todo en la zona actual de Cataluña y $\mathrm{N}$ del País Valenciano-. Estas evidencias, junto con los ejemplos documentados en el sureste de Francia, han sido interpretadas como cráneos de enemigos o de antepasados expuestos en lugares públicos y/o privados con objetivos diversos (Roure y Pernet, 2011). Pero este tipo de prácticas funerarias 'atípicas' no se producen tan solo en los poblados, sino que también se han documentado en algunas cuevas, como en la Cova Freda (Collbató, Barcelona), donde uno de los tres individuos representados se encontraba en conexión directa con materiales de cronología ibérica (Font, 1980).

Algunos investigadores han propuesto que las víctimas humanas pudieron sustituir a los animales en determinados rituales, con un simbolismo destacado para la comunidad (Barrial i Jové, 1990). Esta idea deriva de las evidencias de algunos cráneos humanos depositados junto a ofrendas de animales (Belarte y Sanmartí, 1997; Oliver Foix, 2002-2003). Aun así, hasta el momento, no existen suficientes datos antropológicos que nos permitan afirmar esta hipótesis.

Teniendo en cuenta las características del hallazgo y su relación con el resto de materiales encontrados, consideramos que las marcas observadas sobre los restos humanos se relacionan con un tratamiento o procesado concreto del cadáver (Le Mort, 1982), vinculado a una práctica funeraria compleja, que conlleva al menos el desollado y el descarnado del individuo, junto con un depósito secundario de sus restos.

Esta complejidad exige, por lo tanto, un estudio más exhaustivo de los restos y de sus contextos de hallazgo (Pons y Vargas, 2002), que permita una nueva interpretación sobre la diversidad de rituales funerarios entre los iberos. Asumiendo que las necrópolis no representan el conjunto de las poblaciones ibéricas, las evidencias de inhumaciones dispersas no deben ser consideradas como meras intrusiones de otras épocas en contextos de cronología ibérica.

Las características de la Cueva del Sapo evidencian por tanto la gran diversidad existente dentro del conjunto de las cuevas-santuario ibéricas. Por ello, es importante que sean estudiadas no solo a nivel individual, sino también a escala territorial, analizando ejemplos concretos tal y como se viene haciendo para las cuevas del área central de la Contestania ibérica (Grau, 2000; Grau y Olmos, 2005; Grau y Amorós, 2013). Aunque actualmente no contamos con los datos suficientes que nos permitan llevar a cabo un completo estudio territorial, este tema será tratado en futuros trabajos. A modo de reflexión general, podemos indicar que la Cueva del Sapo se encuentra en una zona limítrofe entre 
los territorios ibéricos del Tossal de Sant Miquel de Llíria (Edeta) y La Carència de Turís (Fig. 1, n.o 2). En esta zona tan solo se han documentado dos cuevas con materiales ibéricos y solo una de ellas se ha relacionado directamente con una actividad ritual: la Cueva Merinel en Bugarra (Martínez Perona, 1992; Blay, 1992), perteneciente al territorio ibérico de Edeta (Bonet y Mata, 1997b). El volumen y características de los materiales de la Cueva del Sapo no parecen ser evidencias de un culto muy difundido entre los habitantes del territorio circundante, sino más bien un lugar destinado a actividades rituales esporádicas. Aunque sería necesario ampliar los estudios sobre esta zona, que al parecer carece de un poblamiento denso, la localización de la cueva nos hace pensar que no existió una vinculación directa con ningún poblado en concreto, sino posiblemente con varios.

\section{Conclusiones}

Las características del conjunto estudiado evidencian sin lugar a dudas un contexto ritual que fue frecuentado entre los ss. V-II a. C. El hecho de que algunos de sus materiales no coincidan con la pauta establecida tradicionalmente para las cuevassantuario nos hace replantearnos la definición tradicional que todavía sigue en vigor para este tipo de contextos, así como la diversidad de actividades rituales que pudieron llevarse a cabo en estos lugares.

El conjunto de materiales estudiados es una evidencia clara de las peculiaridades que presenta esta cueva. Más allá del caliciforme, visto tradicionalmente como marcador de las actividades rituales en las cuevas del Mediterráneo peninsular, en la Cueva del Sapo encontramos recipientes cerámicos muy variados que funcionaron como contenedores de ofrendas, ofrendas en sí mismas o como elementos activos dentro del ritual. Destacan, entre otras, las ánforas o las grandes tinajas, cuyo traslado intencionado a la cueva evidencia un interés que va más allá de la mera funcionalidad. Así mismo, se depositan desde platos, cuencos y escudillas hasta ollas y morteros. Tanto estos recipientes como los objetos metálicos son una evidencia más del uso ritual de esta cueva. Por lo tanto, aunque la acumulación de vasos caliciformes sea una de las evidencias más claras de la actividad ritual en cuevas, se deberían tener en cuenta muchos otros factores (Coll et al., 1994), que otorgan a veces incluso mayor información al conjunto.

Pero, además, la singularidad de la misma aumenta al documentarse la presencia de restos humanos ibéricos sin señales de cremación y con alteraciones antrópicas que evidencian un tratamiento ritual de los individuos inhumados. Por otra parte, la presencia de restos de fauna con un predomino del ciervo y restos poco fragmentados con escasas señales de procesado humano, junto con el depósito de restos de perro con marcas de corte, nos indica que los animales formaron parte de una de las actividades rituales desarrolladas en la cueva, basada en el depósito de los mismos tras su inmolación.

Por desgracia, la remoción producida en el sedimento nos impide conocer la periodicidad de todas estas ofrendas, aunque consideramos viable la existencia de una relación directa entre los restos humanos, los de fauna y parte de los demás materiales.

Las ofrendas que hallamos en los yacimientos de este tipo son tan solo un reflejo de la ritualidad que estuvo presente en estos espacios de culto (Cerrillo, 1990). En el caso de la Cueva del Sapo, la diversidad cronológica y material evidencia la existencia de varias actividades rituales intermitentes que se suceden en el tiempo. Aunque no disponemos de la información suficiente para identificar a los protagonistas de estas ofrendas, el volumen de materiales evidencia la existencia de rituales no generalizados, por lo que no descartamos la posibilidad de que estuvieran en relación con los ritos iniciáticos llevados a cabo en otras cuevas situadas en espacios liminales. Éstos han sido identificados tanto en contextos cultuales ibéricos similares (González-Alcalde 1993, 2002-2003, 2006, 2013; González-Alcalde y Chapa, 1993; Almagro-Gorbea, 1997; Prados, 1996; Moneo, 2003; Grau y Olmos, 2005; Grau y Amorós, 2013; Rueda, 2013, entre otros), como en otras culturas del Mediterráneo (Faure, 1964; Eliade, 1958, 1964, 1984; Brelich, 1969; de Polignac, 1984; Torelli 1984; Dacosta, 1991; Moreau, 1992; Almagro-Gorbea y Álvarez, 1993, entre otros). De ser así, estos rituales relacionados con actividades fuera de la cueva, como pudo ser la caza ritualizada del ciervo, compartirían espacio con el depósito de los dos individuos sometidos a un tratamiento ritual especial, vinculado a la práctica funeraria compleja que documentamos en la cueva. 
Aunque por el momento no podemos avanzar más en la interpretación de las actividades desarrolladas en la Cueva del Sapo, esperamos que las peculiaridades que presenta esta cueva ayuden a marcar un punto de inflexión en los estudios sobre este tipo de contextos, cargados en algunas ocasiones de excesivas generalizaciones. Además, nuestras líneas de trabajo futuras se orientan hacia un estudio territorial que nos permita comprender el significado de este lugar de culto en el contexto específico de su territorio.

\section{Bibliografía}

Abad, L. y Sala, F. (1993): El poblado ibérico de El Oral (San Fulgencio, Alicante). Serie de Trabajos Varios del sıp, 90. Valencia.

Albizuri, S. (2011): "Depósitos de ovicaprinos en ámbito doméstico ibérico. El ejemplo del poblado de Ca n'Oliver (Cerdanyola del Vallès, Barcelona)", $A r$ chaeofauna, 20, pp. 85-101.

Alemán, I.; Botella, M. C. y Ruiz, L. (1997): "Determinación del sexo en el esqueleto postcraneal. Estudio de una población mediterránea actual", Archivo Español de Morfologia, 2, pp. 69-79.

Almagro-Gorbea, M. (1996): "Lobos y ritos de iniciación en Iberia". En Olmos, R. y Santos, J. A. (eds.): Iconografía ibérica e iconografía itálica: propuestas de interpretación y lectura (I Coloquio Internacional: Roma, 1993). Serie Varia, 3. Madrid: csic, pp. 103-127.

Almagro-Gorbea, M. y Álvarez, J. (1993): "La 'sauna' de Ulaca: saunas y baños iniciáticos en el mundo céltico", Cuadernos de Arqueología de la Universidad de Navarra, 1, pp. 177-253.

Amorós, I. (2012): "La Cova de l'Agüela (Vall d'Alcalà, Alicante). Una cueva-santuario en el corazón de la Contestania ibérica", Alberri: Quaderns d'investigació del Centre d'Estudis Contestans, 22, pp. 51-93.

Aparicio, J. (1976): "El culto en cuevas en la región valenciana”. En Homenaje a García y Bellido, I. Revista de la Universidad Complutense, xxv, n. ${ }^{\circ}$ 10, pp. 9-30.

Aparicio, J. (1997): "El culto en cuevas y la religiosidad protohistórica", Quaderns de Prehistòria i Arqueologia de Castelló, 18, pp. 345-358.

Aranegui, C. y Martí Bonafé M. a A. (1995): "Cerámicas procedentes de un alfar ibérico localizado en el Pla de Piquer (Alfara d'Algímia), cerca de Sagunt (València)", Saguntum-PLAV, 28, pp. 131-149.

Aranegui, C.; Mata, C. y Pérez Ballester, J. (1997): Damas y caballeros en la ciudad ibérica: las cerámicas decoradas de Llíria (Valencia). Madrid: Cátedra.
Aura, J. E.; Morales, J. V. y De Miguel, M. P. (2010): "Restos humanos con marcas antrópicas de les coves de Santa Maira”. En Pérez, A. y Soler, B. (coords.): Restos de vida, de muerte: la muerte en la Prehistoria. Valencia: Museu de Prehistòria de València, pp. 169-174.

Badal, E. y Heinz, C. (1991): "Méthodes utilisées en Anthracologie pour l'étude de sites préhistoriques". En II $I^{\text {nd }}$ Deya Conference, Archaeological Techniques, Technology \& Theory, Deya (Mallorca, 1988). BAR Int. Ser., 573. Oxford: Archaeopress, pp. 17-47.

Barrial i Jové, O. (1990): "El ritual de sacrificio en el mundo ibérico catalán”, Zephyrus, xLIII, pp. 243-248.

Belarte, M. C. y Sanmartí, J. (1997): "Espais de culte i practiques rituals a la Catalunya protohistórica", Quaderns de Prehistòria de Castelló, 18, pp. 7-32.

Binford, L. R. (1981): Bones: Ancient Men and Modern Myths. New York: Academic Press.

Blasco, M. F. (1992): Tafonomía y Prehistoria. Métodos y procedimientos de investigación. Monografías arqueológicas, 36. Zaragoza.

Blay, F. (1992): "Cueva Merinel (Bugarra). Análisis de fauna". En Juan Cabanilles, J. (coord.): Estudios de Arqueología ibérica y romana. Homenaje a Enrique Pla Ballester. Serie de Trabajos Varios del sip, 89. Valencia, pp. 283-287.

Bonet, H. y Mata, C. (1997a): "La cerámica ibérica del siglo v a.C. en la Edetania", Recerques del Museu d'Alcoi, 6, pp. 31-47.

Bonet, H. y Mata, C. (1997b): "Lugares de culto edetanos. Propuesta de definición", Quaderns de Prehistòria i Arqueologia de Castelló, 18, pp. 115-146.

Botella, M. C. (1973): "Restos humanos eneolíticos con incisiones de la provincia de Granada", Anales del Desarrollo, 17 (41-42), pp. 401-423.

Botella, M. C. y Alemán, I. (1998): "Las huellas del canibalismo", Archivo Español de Morfología, 3, pp. 75-86.

Botella, M. C.; Alemán, I, y Jiménez, S. A. (1999): Los huesos humanos. Manipulación y alteraciones. Barcelona: edic. Bellaterra.

Botella, M. C.; Jiménez, S. A.; Alemán, I.; Du Souich, Ph. y García, C. (2000): "Evidencias de canibalismo en el Neolítico español”. En Caro, L.; Rodríguez, H.; Sánchez, E.; López, B. y Blanco, M. J. (eds.): Tendencias actuales de Investigación en la Antropología Física Española. León: Univ. de León, pp. 43-56.

Botella, M. C.; Jiménez, S. A.; Alemán, I.; Du Souich, Ph. y García, C. (2003): "Canibalismo en dos lugares neolíticos espańoles. Estudio comparativo”. En Aluja, M. P.; Malgosa, A. y Nogués, R. M. (eds.): Antropologia y Biodiversidad, vol. I. Madrid: edic. Bellaterra, pp. 65-77.

Brelich, A. (1969): Paides e parthenoi. Roma: edizioni dell'Ateneo. 
Brothwell, D. R. (1987): Desenterrando huesos. La excavación, tratamiento y estudio de restos del esqueleto humano. México: FCE.

Bull, G. y Payne, S. (1982): "Tooth eruption and epiphisial fusion in pigs and wild boar". En PaYne, S.; WiLson, B. y Grigson, C. (eds.): Ageing and sexing animal bones from archaeological sites. BAR Int. Ser., 109. Oxford: Archaeopress, pp. 55-72.

Cabré, E. y Morán, J. A. (1979): "Ensayo tipológico de las fíbulas con esquema de la Tène en la Meseta Hispánica”, Boletín de la Asociación Española de Amigos de la Arqueología, 11-12, pp. 10-26.

Cabré, E. y Morán, J. A. (1982): “Ensayo cronológico de las fíbulas con esquema de la Tène en la Meseta Hispánica”, Boletín de la Asociación Española de Amigos de la Arqueología, 15, pp. 4-27.

Cabrera, A. (2010): El ritual del sacrificio de animales en la cultura ibérica. Una perspectiva arqueológica. Madrid.

Cerrillo, E. (1990): "Arqueología de las religiones primitivas y arqueología de las religiones organizadas", Zephyrus, XLIII, pp. 189-192.

Chabal, L. (1997): Forêts et sociétés en Languedoc (Néolithique final, Antiquité tardive). L'anthracologie, méthode et paleoecologie. Documents d'Archéologie Française, 63. Paris.

Coll, R.; Cazorla, F. y BayÉs, F. (1994): “El santuari ibèric de la cova de les Encantades del Montcabrer (Cabrera de Mar, Barcelona). Estudi preliminar", Laietania, 9, pp. 33-86.

Colominas, L. (2008): "Els animals en el conjunt de les practiques socials desenvolupades a l'establiment rural de Mas Castellar (Pontós, Girona)", Cypsela, 17, pp. 219-232.

Cuadrado, E. (1978): "Fíbulas de la Tène en 'El Cigarralejo"”, Trabajos de Prehistoria, 35, pp. 307-336.

Cuadrado, E. (1987): La necrópolis ibérica de "El Cigarralejo" (Mula, Murcia). Madrid: Centro de Estudios Históricos.

Cunha, E.; Baccino, E.; Martrille, L.; Ramsthaler, F.; Prieto, J.; Schuliar, Y.; Lynnerup, N. y Cattaneo, C. (2009): "The problem of aging human remains and living individuals: a review”, Forensic Science International, 193, pp. 1-13. http://dx.doi.org/10.1016/j.forsciint.2009.09.008

Curé, A. M. (2010): 'Réflexions sur l'utilisation culinaire des mortiers protohistoriques en céramique: Le cas du Languedoc Méditerranéen à l'âge du Fer", SaguntumPLAV, extra-9, pp. 189-198.

Dacosta, Y. (1991): Initiations et sociétés sécrètes dans l'Antiquité gréco-romaine. Paris: Berg International Édits.

De la Vega, J. (1987): “Contribució catalana a l'inventari de les probables coves santuari ibèriques", Fonaments, 6, pp. 171-192.
De Polignac, F. (1984): La naissance de la cité grecque. Paris: Découverte.

Díes, E.; Bonet, H.; Álvarez, N. y Pérez Jordá, G. (1997): "La Bastida de les Alcusses (Moixent): resultados de los trabajos de excavación y restauración. Años 1990-1995", Archivo de Prehistoria Levantina, xxII, pp. 215-295.

Dodson, P. y Wexlar, D. (1979): “Taphonomic investigations of owl pellets", Paleobiology, 5 (3), pp. 275-284.

Eliade, M. (1958): Rites and symbols of initiation. London: Harvill.

Eliade, M. (1964): Initiations, rites, sociétés secrètes. Paris: Gallimard.

Eliade, M. (1984): Iniciaciones misticas. Madrid: Taurus.

Faure, P. (1964): Fonctions des cavernes crétoises. Paris: École Française d'Athènes.

Ferembach, D.; Schwidetzky, I. y Stloukal, M. (1980): "Recommendations for age and sex diagnoses of skeletons", Journal of Human Evolution, 9, pp. 517-549. http://dx.doi.org/10.1016/0047-2484(80)90061-5

Fernández-Jalvo, Y.; Carlos Díez, J. C.; Cáceres, I. y Rosell, J. (1999): "Human cannibalism in the Early Pleistocene of Europe (Gran Dolina, Sierra de Atapuerca, Burgos, Spain)", Journal of Human Evolution, 37 (3), pp. 591-622.

http://dx.doi.org/10.1006/jhev.1999.0324

Fletcher, D.; Pla, E. y Alcácer, J. (1965): La Bastida de les Alcuses I (Mogente-Valencia). Valencia: Serie de Trabajos Varios del sip, 24.

Fletcher, D.; Pla, E. y Alcácer, J. (1969): La Bastida de les Alcuses II (Mogente-Valencia). Valencia: Serie de Trabajos Varios del sip, 25.

Gil-Mascarell, M. (1975): "Sobre las cuevas ibéricas del País Valenciano. Materiales y problemas", SaguntumPLAV, 11, pp. 281-332.

Gil-Mascarell, M. (1977): "Excavaciones en la cuevaritual ibérica de Villagordo del Cabriel (Valencia)". En XIV Congreso Nacional de Arqueología (Vitoria 1975). Zaragoza, pp. 705-712.

González Reyero, S.; Sánchez-Palencia, F. J.; Flores, C. y López Salinas, I. (2014): "Procesos de apropiación y memoria en el sureste peninsular durante la Segunda Edad del Hierro: Molinicos y la Umbría de Salchite en la construcción de un territorio político", Zephyrus, LxxiII, pp. 149-170. http://dx.doi.org/10.14201/zephyrus201473149170

GonZÁlez-AlCAldE, J. (1993): "Las cuevas santuario ibéricas en el País Valenciano: Un ensayo de interpretación”, Verdolay, 5, pp. 67-78.

GonZÁlez-Alcalde, J. (2002-2003): “Cuevas-refugio y cuevas-santuario en Castellón y Valencia: Espacios de resguardo y entornos iniciáticos en el mundo ibérico", Quaderns de Prehistòria i Arqueologia de Castelló, 23, pp. $187-240$ 
GonzÁlez-Alcalde, J. (2005): “Una aproximación a las cuevas-santuario ibéricas en el País Valenciano", $M a-$ drider Mitteilungen, 46, pp. 87-103.

GonzÁlez-Alcalde, J. (2006): “Totemismo del lobo, rituales de iniciación y cuevas-santuario mediterráneas e ibéricas", Quaderns de Prehistòria i arqueología de Castelló, 25, pp. 249-269.

GonZÁlez-Alcalde, J. (2009): "Una aproximación cultural a los vasos caliciformes ibéricos en cuevas-santuario y yacimientos en superficie", Quaderns de Prehistòria $i$ Arqueologia de Castelló, 27, pp. 85-107.

GonzÁlez-Alcalde, J. (2011): "Una reflexión genérica sobre el sacerdocio ibérico en el contexto de las cuevas-santuario", Recerques del Museu d'Alcoi, 20, pp. $137-150$.

González-Alcalde, J. (2013): Las Cuevas-Santuario y su incidencia en el contexto social del Mundo Ibérico. Madrid.

González-Alcalde, J. y Chapa, T. (1993): “Meterse en la boca del lobo. Una aproximación a la figura del carnasier en la religión ibérica", Complutum, 4, pp. 169-174.

Grau, I. (1996): "La Cova dels Pilars (Agres. El Comtat). Aportació a l'estudi de les coves-santuari ibèriques", $\mathrm{Al}$ berri: Quaderns d'investigació del Centre d'Estudis Contestans, 9, pp. 79-106.

Grau, I. (2000): “Territorio y lugares de culto en el área central de la Contestania ibérica", Quaderns de Prehistòria i Arqueología de Castelló, 21, pp. 195-226.

Grau, I. y Amorós, I. (2013): "La delimitación simbólica de los espacios territoriales: el culto en el confín y las cuevas-santuario". En Rísquez, C. y Rueda, C. (eds.): Santuarios íberos: territorio, ritualidad y memoria (Congreso Int. 'El Santuario de la Cueva de La Lobera de Castellar. 1912-2012', Jaén, 2012). Jaén: Asociación para el desarrollo rural de la Comarca de El Condado, pp. 183-212.

Grau, I. y Olmos, R. (2005): "El ánfora ática de la Cova dels Pilars", Archivo Español de Arqueología, 78, pp. 49-77. http://dx.doi.org/10.3989/aespa.2005.v78.73

Grau, I. y Reig, C. (2002-2003): "Sobre el uso de metales en la Contestania Ibérica: Las evidencias de La Serreta”, Recerques del Museu d'Alcoi, 11-12, pp. 101-150.

GuÉrin, P. (2003): El Castellet de Bernabé y el horizonte ibérico pleno edetano. Serie de Trabajos Varios del sip, 101. Valencia.

Hillson, S. (1986): Teeth (Cambridge Manuals in Archaeology). Cambridge: cup.

Horard-Herbin, M. P. (2000): “Dog management and use in the late Iron Age: the evidence from gallic site of Leroux (France)". En Crockford, S. J. (ed.): Dogs through time: an archaeological perspective. BAR Int. Ser., 889. Oxford: Archaeopress, pp. 115-121.
Iborra, M. P. (2004): La ganadería y la caza desde el Bronce Final Hasta el Ibérico Final en el territorio valenciano. Serie de Trabajos Varios del sip, 103. Valencia.

Iniesta, A. (1983): Las fíbulas de la región de Murcia. Murcia: Edit. Regional de Murcia.

Jacquiot, C.; Trenard, Y. y Dirol, D. (1973): Atlas d'anatomie des bois des angiospermes (Essences feuilles). Paris: Centre Téchnique du Bois.

Jiménez Brobeil, S. A.; Ortega Vallet, J. A. y García SÁnCHEZ, M. (1986): "Incisiones intencionales sobre huesos humanos del Neolítico de la cueva de Malalmuerzo (Moclín, Granada)", Antropología y Paleoecologia Humana, 4, pp. 34-65.

Le Mort, F. (1982): "Actions intentionnelles sur les os humains", Histoire et Archéologie. Les dossiers, 66, pp. 28-32.

López Bertrán, M. y Vives-Ferrándiz, J. (2009): “Menjar, beure, cremar. Els rituals com a pràctiques relacionals durant l'Edat del Ferro", Citerior, v, pp. 163-88.

Lorrio, A. J.; Moneo, T.; Moya, F.; Pernas, S. y SánChez de Prado, M. a D. (2006): "La Cueva Santa del Cabriel (Mira, Cuenca): lugar de culto antiguo y ermita cristiana", Complutum, 17, pp. 45-80.

Lyman, R. L. (1994): Vertebrate Taphonomy (Cambridge Manuals in Archaeology). Cambridge: cup. http://dx.doi.org/10.1017/CBO9781139878302

Lyman, R. L. (2008): Quantitative Paleozoology (Cambridge Manuals in Archaeology). Cambridge: cup. http://dx.doi.org/10.1017/CBO9780511813863

Mariezkurrena, K. (1983): "Contribución al conocimiento del desarrollo de la dentición y el esqueleto post-craneal de Cervus elaphus", Munibe, 35, pp. 149-202.

Martí Bonafé, M. a A. (1990): "Las Cuevas del Puntal del Horno Ciego. Villargordo del Cabriel, Valencia", Saguntum-PLAV, 23, pp. 141-182.

Martin, D. L. y Frayer, D. W. (eds.) (1997): Troubled Times. Violence and Warfare in the Past. Amsterdam: Gordon and Breach Publishers.

Martínez Perona, J. V. (1992): "El santuario ibérico de la Cueva Merinel (Bugarra). En torno a la función del vaso caliciforme". En Juan Cabanilles, J. (coord.): Estudios de Arqueología ibérica y romana. Homenaje a Enrique Pla Ballester. Serie de Trabajos Varios del sip, 89. Valencia, pp. 261-282.

Martínez Valle, A. y Castellano, J. J. (1996): “Conjunto de fusayolas ibéricas de dos cuevas santuario de la comarca de Requena-Utiel”. En XIII Congreso Nacional de Arqueologia (Elche, 1995), vol. I, pp. 552-536.

Mata, C. (1991): Villares (Caudete de las Fuentes, Valencia): origen y evolución de la Cultura Ibérica. Trabajos Varios del sip, 88. Valencia.

Mata, C. y Bonet, H. (1992): "La cerámica ibérica: ensayo de tipología”. En Juan Cabanilles, J. (coord.): Estudios 
de Arqueología ibérica y romana. Homenaje a Enrique Pla Ballester. Valencia: Serie de Trabajos Varios del SIP 89, pp. 117-173.

McParland, L. C.; Collinson, M. E.; Scott, A. C.; Campbell, G. y Veal, R. (2010): "Is vitrification in charcoal a result of high temperature burning of wood?", Journal of Archaeological Science, 37 (10), pp. 2679-2687.

http://dx.doi.org/10.1016/j.jas.2010.06.006

Meindl, R. S. y Lovejoy, C. O. (1985): "Ectocranial suture closure: a revised method for the determination of skeletal age at death based on the lateral anterior sutures", American Journal of Physical Anthropology, 68, pp. 57-66. http://dx.doi.org/10.1002/ajpa.1330680106

MÉniel, P. (1992): Les sacrifices d'animaux chez les gaulois. Paris: Éditions Errance.

MÉniel, P. (2012): "Archézoologie et sanctuaires: quelques développements récents". En De Cazanove, O. y MÉNIEL, P. (dirs.): Étudier les lieux de culte de Gaule romaine (Table-ronde Dijon, 2009). Montagnac: Edit. Monique Mergoil.

Moneo, T. (2003): Religio iberica: santuarios, ritos y divinidades (siglos VII-I a.C.). Madrid: RAH.

Moreau, A. (1992): "Initiation en Grèce antique", Dialogues d'Histoire Ancienne, 18 (1), pp. 191-244. http://dx.doi.org/10.3406/dha.1992.1988

Ocharán, J. A. (2013): “Aproximación al estudio de los santuarios rupestres ibéricos de la región de Murcia: La Nariz (Moratalla, Murcia)". En RísQuez, C. y RueDA, C. (eds.): Santuarios iberos: territorio, ritualidad y memoria. Congreso Int. "El Santuario de la Cueva de La Lobera de Castellar. 1912-2012” (Jaén, 2012). Jaén: Asociación para el desarrollo rural de la Comarca de El Condado, pp. 289-303.

Oliver, A. (2002-2003): “Sacrificios y 'mala muerte' en el registro arqueológico de los yacimientos ibéricos”, Espacio, Tiempo y Forma, Serie I. Prehistoria y Arqueología, 16-17, pp. 391-417.

Oliver, A. (2010): “Cova dels Orguens, la Vall d'Uixó (Castellón)". Un nuevo asentamiento en cueva”, Quaderns de Prehistòria i Arqueologia de Castelló, 28, pp. 191-205.

Olivier, G. (1960): Practique anthropologique. Paris: Vigot Frères.

Olmos, R. y Grau, I. (2005): "El Vas dels Guerrers de La Serreta”, Recerques del Museu d'Alcoi, 14, pp. 79-98.

PAYNE, S. (1982): "Eruption and wear in the mandibular dentition as a guide to ageing Turkish Angora goats". En Payne, S.; Wilson, B. y Grigson, C. (eds.): Ageing and sexing animal bones from archaeological sites. BAR Int. Ser., 109. Oxford: Archaeopress, pp. 155-206.

Pérez Ripoll, M. (1992): Marcas de carnicería, fracturas intencionales y mordeduras de carnivoros en huesos prehistóricos del Levante español. Alicante: Instituto de Cultura Juan Gil-Albert.

Pla Ballester, E. (1968): "Instrumentos de trabajo ibéricos en la región valenciana”. En TARradell, M. (dir.): Estudios de economía antigua de la Peninsula Ibérica. Barcelona: Vicens-Vives, pp. 143-190.

Pla Ballester, E. (1985): "Excavación de urgencia en la Cueva del Sapo, del término de Chiva”. En Pla BAllester, E. (coord.): La Labor del SIP y su Museo en 1983. Valencia: sip, pp. 56-60.

Prados, L. (1996): "Los ritos de paso y su reflejo en la toréutica ibérica”. En Olmos, R. y SAntos, J. A. (eds.): Iconografía ibérica e iconografía itálica: propuestas de interpretación y lectura. I Coloquio Internacional: Roma, 1993. Serie Varia, 3. Madrid: csic, pp. 273-282.

Quesada, F. (1997): El armamento ibérico. Estudio tipológico, geográfico, funcional, social y simbólico de las armas en la Cultura Ibérica (siglos VI-I a.C.). Montagnac: edit. Monique Mergoil.

RAGA, M. (1995): "El poblado ibérico de 'La Covalta' (Albaida, Valencia y Agres, Alicante): estudio de las cerámicas ibéricas y su aportación a la problemática sobre su cronología", Saguntum-PLAV, 29, pp. 113-122.

Reitz, E. J. y Wing, E. S. (1999): Zooarchaeology (Cambridge Manuals in Archaeology). Cambridge: cup.

Rivas-Martínez, S. (1987): Memoria del mapa de series de vegetación de España 1: 400.000. Madrid: ICONA.

Roure, R. y Pernet, L. (2001): Des rites et des Hommes. Les pratiques symboliques des Celtes, des Ibères et des Grecs en Provence, en Languedoc et en Catalogne. Paris: Édit. Érrance.

RuedA, C. (2013): "Ritos de paso de edad y ritos nupciales en la religiosidad ibera: algunos casos de estudio". En Rísquez, C. y Rueda, C. (eds.): Santuarios iberos: Territorio, ritualidady memoria (Congreso Int. 'El Santuario de la Cueva de La Lobera de Castellar. 1912-2012', Jaén, 2012). Jaén: Asociación para el desarrollo rural de la Comarca de El Condado, pp. 341-384.

SANCHIS, A. (2012): Los lagomorfos del Paleolitico medio en la vertiente mediterránea ibérica. Humanos y otros predadores como agentes de aporte y alteración de los restos óseos en yacimientos arqueológicos. Serie de Trabajos Varios del SIP, 115. Valencia.

SArrión, I. (1990): "Estudio de la fauna de la Cueva ir". En Martí, M. A.: "Las Cuevas del Puntal del Horno Ciego (Villagordo del Cabriel, Valencia)", Saguntum-PLAV, 23, pp. 180-182.

SAUER, N. J. (1998): "The timing of injuries and manner of death: distinguishing among antemortem, perimortem and postmortem trauma”. En Reichs, K. J. (ed.): Forensic osteology: advances in the identification of human remains. Springfield, IL: C. C. Thomas, pp. 321-332.

SchweIngruber, F. H. (1990): Anatomie europäischer Hölzer. Bern und Stuttgart: HAUPT. 
Serrano, D. y Fernández J. (1992): "Cuevas rituales ibéricas en la provincia de Valencia”, Al-Gezira, 7, pp. 11-35.

Silver, I. A. (1969): "The ageing of domestic animals". En Brothwell, D. R. y Higgs, E. S. (eds.): Science in Archaeology. London: Thames and Hudson, pp. 283-302.

TARradell, M. (1973): "Cuevas sagradas o cuevas santuario: un aspecto poco valorado de la religión ibérica", Memorias de 1973 del Instituto de Arqueología y Prehistoria de la Univ. de Barcelona, pp. 25-40.

Torelli, M. (1984): Lavinio e Roma. Riti iniziatici e matrimonio tra archeologia e storia. Roma: ed. Quasar.

TORTAJADA, G. (2012): "Las herramientas de carpintería en la Bastida de les Alcusses (Moixent, Valencia)", Archivo de Prehistoria Levantina, xxix, pp. 289-308.

Turner, C. G. y Turner, J. A. (1999): Man Corn. Cannibalism and Violence in the Prehistoric American Southwest. Salt Lake City: The University of Utah Press.

Ubelaker, D. H. (1989): Human Skeletal Remains. Excavation, Analysis, Interpretation. Manuals of Archeology, 2. Washington: Taraxacum.

Vidal, V.; Martí, M. a A. y Mata, C. (1997): "La cerámica ibérica de la segunda mitad del s. v a.C. en Los Villares
(Caudete de las Fuentes, Valencia): Formas y decoraciones", Recerques del Museu d'Alcoi, 6, pp. 49-59.

VILLA, P. (1992): "Cannibalism in prehistoric Europe", Evolutionary Anthropology, 1 (3), pp. 93-104. http://dx.doi.org/10.1002/evan.1360010307

Villa, P.; Bouville, C.; Courtin, J.; Helmer, D.; Mahieu, E.; Shipman, P.; Belluomini, G. y Branca, M. (1986): "Cannibalism in the Neolithic", Science, 233, pp. 431-437.

http://dx.doi.org/10.1126/science.233.4762.431

Villa, P. y Mahieu, E. (1991): "Breakage Patterns of Human Long Bones", Journal of Human Evolution, 21, pp. 27-48. http://dx.doi.org/10.1016/0047-2484(91)90034-S

Vives-Ferrándiz, J. (2004): “Trípodes, ánforas y consumo de vino: acerca de la actividad comercial fenicia en la costa oriental de la península ibérica", Rivista di Studi Fenici, 32 (2), pp. 9-33.

Walker, P. L. (2001): "A Bioarchaeological Perspective on the History of Violence", Annual Review of Anthropo$\log y, 30$, pp. 573-596. http://dx.doi.org/10.1146/annurev.anthro.30.1.573

White, T. D. (1992): Prehistoric Cannibalism at Mancos 5MTUMR-2346. Princeton: PUP. 